Federal Reserve Bank of Dallas

Globalization and Monetary Policy Institute

Working Paper No. 219

http://www.dallasfed.org/assets/documents/institute/wpapers/2014/0219.pdf

\title{
The Role of Two Frictions in Geographic Price Dispersion: When Market Friction Meets Nominal Rigidity ${ }^{*}$
}

\author{
Chi-Young Choi \\ University of Texas at Arlington \\ Horag Choi \\ Monash University
}

December 2014

\begin{abstract}
This paper empirically investigates and theoretically derives the implications of two frictions, market friction and nominal rigidity, on the dynamic properties of intra-national relative prices, with an emphasis on the interaction of the two frictions. By analyzing a panel of retail prices of 45 products for 48 cities in the U.S., we make two major arguments. First, the effect of each type of friction on the dynamics of intercity price gaps is quite different. While market frictions arising from physical distance and transportation costs contribute significantly to volatile and persistent movements of intercity price disparities, nominal rigidity is associated with higher persistence, but not with a greater volatility of the intercity price disparity. This empirical evidence is different from what is predicted by standard theoretical models based on price stickiness. Second, the strength of the marginal effect of a market friction hinges on the extent of nominal rigidity, in a counteracting manner. The marginal effect of a market friction dwindles as the extent of price stickiness increases. We provide an alternative theoretical explanation for this finding by extending the statedependent pricing (SDP) model of Dotsey et al. (1999) and show that our two-city model with nominal rigidity and market frictions can successfully explain the salient features of the dynamic behavior of intercity price differences.
\end{abstract}

JEL codes: E31, F15, L16, R12

\footnotetext{
* Cy Choi, Department of Economics, University of Texas at Arlington, 701 S. West Street, Arlington, TX 76019. 817-272-3860. cychoi@uta.edu. Horag Choi, Department of Economics, Monash University, 900 Dandenong Road, Caulfield East, VIC 3145, Australia. +61-0-3-9903-2848. Horag.choi@monash.edu. The authors have benefited from helpful comments from Daniel Allen, Nathan Balke, Anton Cheremukhin, Alex Chudik, Yongwan Chun, Anthony Murphy, Róisín O’Sullivan, Moto Shintani, Mike Spossi, Adriaan Soetevent, Mike Ward, Mark Wynne, Carlos Zarazaga, and the participants at the 10th annual International Industrial Organization Conference (IIOC) in Washington, D.C., the 2012 Midwest Macroeconomics Meetings at the University of Notre Dame, the 15th KEA International Conference in Seoul, Korea, the Federal Reserve Bank of Dallas, and Baylor University. The authors would also like to thank Arsalan Nadeem for excellent research assistance and Moto Shintani for sharing the data on distribution margins. The views in this paper are those of the authors and do not necessarily reflect the views of the Federal Reserve Bank of Dallas or the Federal Reserve System.
} 


\section{Introduction}

"There appears to be potential for a marriage of the new-Keynesian literature on menu costs and the new trade literature emphasizing the role of geography." - Engel and Rogers (1996, p.1123)

Price differentials across locations have long been an important issue for both researchers and policymakers alike. ${ }^{1}$ According to the tenet of the Law of One Price (LOP), the same good should sell for the same price everywhere in a fully flexible price world with no obstacles to trade. In practice, however, geographic price dispersion is large and persistent even within a national border where trade barriers are relatively low (e.g., Crucini et al., 2010, 2012; Engel and Rogers, 2001). Economic theories suggest numerous factors conducive to the observed spatial price dispersion, such as transportation costs, other trade costs, and menu costs, that are pertinent in the intra-national setting. Among them a leading explanation in the literature is that market segmentation arises due to transport costs (henceforth, 'market friction') which drives a wedge between relative prices in different locations by limiting arbitrage opportunities (e.g., Rogoff 1996). As a popular metric for market friction, the role of distance in geographic price differentials is well established, such that price difference is greater and more persistent between cities located farther apart (e.g., Anderson and van Wincoop 2004; Choi and Choi 2014). Another well-known contributing factor to the large and persistent movements of price differences is 'nominal rigidity' due to sluggish adjustment of prices, in which relative price fluctuations are thought to result from the interaction of fundamental shocks, e.g., monetary and productivity shocks, and sticky prices. Starting with Dornbusch (1976), price stickiness has been incorporated in many macroeconomic models as an important mechanism capable of generating persistent and volatile movements in relative prices (e.g., Bergin and Feenstra 2001, Carvalho and Nechio 2011, Kehoe and Midrigan 2011). In fact, empirical evidence based on micro-data generally put forth supportive evidence that relative prices are more persistent for the products with stickier price adjustment (e.g., Engel and Rogers 2001, Crucini et al. 2010). For all of its theoretical appeal and empirical support on the importance of the two frictions, relatively little work has explored their interplay in explaining the observed movements of intercity relative prices. ${ }^{2}$ If mechanisms exist that lead one type of friction to either amplify or dampen the impact of the other

\footnotetext{
${ }^{1}$ From the perspective of policymakers, large and persistent price differences across locations within a national border imply distortions in efficient resource allocation due to market segmentation.

${ }^{2}$ The literature on the purchasing power parity (PPP) and LOP has largely discussed the two frictions in isolation with few notable exceptions including Engel and Rogers (1996,2001, hereafter ER) and Crucini, Shintani and Tsuruga (2010,2012, henceforth CST).
} 
on intercity relative prices, a focus of these interactions could greatly enhance our understanding of these intercity price dynamics.

The primary objective of this study is to examine both empirically and theoretically the roles of market friction and nominal rigidity in accounting for dynamic behaviors of price differences across locations, with a particular emphasis placed on the interface between the two frictions. To this end, we use retail price data from the American Chamber of Commerce Researchers Association (ACCRA) for 45 individual products across 48 U.S. cities, which enable us to investigate the absolute level of price difference. With the coverage of various cities for long time span, the ACCRA data set is well suited to the analysis of intercity relative price dynamics. Moreover, the intra-national data set facilitates our focus on market friction and nominal rigidity by ruling out the influences of external factors such as nominal exchange rates and trade policies that are known to play a dominant role across national borders. ${ }^{3}$ Our study is centered on two key questions: (1) whether and how each friction contributes to the dynamic behavior observed in price differences across cities; and (2) how the two frictions interact each other in creating the observed intercity price differences. We address these questions empirically first, and then develop a theoretical model to explain the empirical regularities. The current study is certainly not the first to make this kind of attempt. Instead, our study complements and extends the growing literature examining micro-data on LOP deviations in several directions. As summarized in Table 1, a few previous studies parse out contributing factors to the cross-regional price dispersions, but with different datasets and concentration. To our knowledge, ER (1996) is the first who stress the importance of simultaneous consideration of both nominal rigidity and market friction in explaining deviations from the LOP. In their pioneering work using cross-country data, ER address the question of whether variability of relative prices is due solely to market segmentation or to some other factors like sticky nominal prices. The authors conclude that both distance and sticky prices account for a significant amount of the variation in the relative prices in different cities, albeit price stickiness plays a more dominant role. They further point out a possible endogeneity of the two frictions by noting that price stickiness may be dependent upon market segmentation, but they do not explore this issue further. In turn, ER advocate for 'bringing in independent evidence' on price stickiness, such as the frequency of price adjustment across industries, along with transportation costs and marketing and distribution costs.

\footnotetext{
${ }^{3}$ Because arbitrage within a national border is, in principle, not obstructed by policy-imposed trade barriers or exchange rate fluctuations, intercity price differences for identical products can be largely attributed to transportation costs, nominal rigidities or other local costs.
} 
Our findings confirm those of previous studies that both market friction and nominal rigidity are significant and robust determinants of the intercity price differences. While market friction is responsible for more persistent and more volatile movements in good-level relative prices, the role of nominal rigidity is rather mixed. Persistence of intercity price differences tends to rise with the extent of nominal rigidity, but volatility declines with it. Although this result accords well with the growing micro-data evidence that stickier prices are positively associated with persistence but negatively with volatility in relative prices (e.g., ER 2001, Kehoe and Midrigan 2011, CST 2010), it does not fit the standard theoretical models based on sticky prices (à la New Keynesian models) that typically predict a one-for-one relationship between the degree of price stickiness and volatility of relative prices (e.g., Carvalho and Nechio 2011). In a model featuring Calvo-type time dependent pricing (TDP), for instance, Kehoe and Midrigan (2011) show that greater price stickiness is predicted to be associated with greater conditional volatility and persistence in sectoral real exchange rates (RERs). As shown by the authors, however, this prediction is not borne out by their data. A similar loose link between theory and data has been found by CST (2010) based on a micro price data for the Japanese cities. While their Calvo-type stochastic general equilibrium model predicts a positive association between price stickiness and volatility of deviations from the LOP, their empirical evidence points toward an inverse relationship between them. ${ }^{4}$ Since standard models do not fully account for the empirical regularities, we propose alternative theoretical models to explain the empirical regularities. In a modified state-dependent pricing (SDP) model of Dotsey et al. (1999) that embed both market friction and nominal rigidity, we show that our two-city model can successfully explain the salient feature of intercity price differences including the inverse association between price stickiness and volatility.

Another important motivation of this study concerns the interaction between nominal rigidity and market friction as a driving force behind the dynamic behavior of relative prices. When we look at the interplay of the two frictions in the spirit of ER $(1996,2001)$, we discover significant evidence of a meaningful association between variations in price stickiness and the marginal effect of market friction. On a priori grounds, one may expect that the products with stickier price adjustment, in which movements of relative prices are known to be more persistent, are likely to have a bigger marginal impact of market friction. Contrary to our initial intuition built on the previous work, the

\footnotetext{
${ }^{4}$ As summarized in Table 1, CST employs two different theoretical models for two different data sets to explain separately the empirical regularities on persistence and volatility of intercity relative prices.
} 
impact of market friction on the dynamics of intercity price differences diminishes as the degree of price stickiness increases. Put alternatively, marginal effect of the market friction is stronger for the products whose prices are adjusted more frequently. A rationale for this seemingly counter-intuitive result is that pass-through from marginal costs to retail price is larger when nominal rigidity is lower in a given location, but differences in pass-through occur across locations in the presence of market friction. Firms with a lower degree of nominal rigidity have larger pass-through as they can change prices more frequently, but pass-through to other cities could be smaller if market is segmented by distance or transport costs (henceforth, TC). This gives rise to more volatile and persistent movements of relative prices across cities. So, the impact of differential pass-through due to market friction is more important when prices are less sticky. This feature of empirical evidence is also explained by our two-city SDP model in which price rigidity is associated with a smaller marginal effect of market friction on the volatility and persistence in cross-city price differences.

The remainder of this paper is structured as follows. The next section briefly outlines the data used in the paper and provides a preliminary analysis of the data. Section 3 lays out an empirical analysis with a focus on the role of two frictions in characterizing the dynamic behavior of intercity relative prices. The interplay of the two frictions is also spelled out in this section. Section 4 presents a two-city SDP model, and studies its implications for our empirical findings. Section 5 concludes the paper. The Appendix contains a detailed description of the data and theoretical model derivations.

\section{$2 \quad$ Data and preliminary analysis}

This paper uses micro price data from the American Chamber of Commerce Researchers Association (ACCRA) retail price survey publication, Cost of Living Index. As retail prices for individual goods and services, the ACCRA data are informative not only on the absolute size of price discrepancies between locations, but on the relative behavior over time. In consequence, the dataset suits the purpose of this study to analyze the precise implications of two frictions on the dynamic properties of intercity price gaps. The survey data are available every quarter since 1968.Q1, but the time series data have occasional missing observations due to frequent revisions in the coverage of cities and products. After dropping any series that have missing observations for more than two consecutive quarters, we end up with the sample of prices for 45 narrowly defined goods and service across 48 U.S. cities during 1985-2009, that appeared in roughly 90 percent of the quarterly surveys. As a

result, we have $1,128\left(=\frac{48 \times 47}{2}\right)$ city pairs for 45 products, resulting in more than 50,000 inter-city 
relative price series. For the sake of exposition, here we give a brief description of the dataset, but more detailed discussions can be found in the previous work using the ACCRA data (e.g., Parsley and Wei 1996, O'Connell and Wei 2002, CST 2012). ${ }^{5}$ Summary statistics on the price differences at the product level is provided in tabular form in Table A.1 in the Appendix.

As arguably the closest private sector substitute for the BLS micro-price data, the ACCRA dataset has several appealing features to our study. A main advantage of our data must be a wide locational coverage - 48 U.S. cities - which is more extensive than that of any other micro datasets used in the literature, especially compared to the BLS data. This feature of the data is crucial for our study in light of its focus on the intercity relative prices. Another useful aspect of our dataset is that the sample covers a relatively long time span, 1985.Q1 to 2009.Q4, which facilitates our empirical analysis on the dynamic properties of relative prices. Although the data cover a narrower set of products than the BLS micro-data, it contains information on 45 goods and service products that are highly homogeneous across locations, such as "2 liter can of Coca-Cola", "3 pound can of Crisco's Shortening", and "McDonald hamburger". This specificity of product definition allows us not just to assess the absolute size of price differences between locations, but also to pin down the exact location of the mean of relative prices toward which the price differences converge. In this vein, it is fair to claim that our data set arguably has an edge over the increasingly used micro data from BLS. With that said, one clear drawback of working with the ACCRA data must be on the low frequency of data observations. While recent evidence from the micro-data literature (e.g., Bils and Klenow 2004, Nakamura and Steinsson 2008) shows that many retail prices tend to be set weekly or monthly, prices in the ACCRA data are observed and collected at a quarterly frequency. Since our focus lies in the dynamic properties of citypair price differences, such as temporal variance and persistence, however, this limitation seems unlikely to be consequential to our qualitative conclusions, although we are well aware that it may lead to an overestimation of the persistence in relative prices due to the well-known temporal aggregation bias (e.g., Taylor 2001, Choi et al. 2006). ${ }^{6}$ Moreover, short of

\footnotetext{
${ }^{5}$ A clear trade-off exists between data span and data coverage. Since the focus of our study rests on the dynamics of inter-city relative prices, we choose the breadth of coverage in terms of available cities and products over the length of time. Another important motivation for focusing on the post-1985 data is to get around possible structural breaks in the stochastic properties of good prices triggered by the onset of the Great Moderation. Our data set is more comprehensive than those employed in the previous studies. Parsley and Wei (1996) adopted 51 goods and 48 cities and O'Connell and Wei (2002) studied 48 products for 24 cities over the period 1975.Q1-1992.Q4 that encompasses both the Great Inflation and the Great Moderation periods. CST (2012) recently adopted a comparable data set to ours covering 48 products and 52 cities, but with a much shorter data span of 1990-2007.

${ }^{6}$ There are several criticisms on the use of the ACCRA data. First, it is not as comprehensive as disaggregated price indices in terms of product coverage. Second, it is more susceptible to the marketing behavior of one or a few
} 
alternative data sources in terms of the locational coverage for homogeneous quality for many cities scattered around the country renders us to stick to this dataset.

Figure 1 displays the geographical distribution of the 48 cities based on their sizes in terms of nominal income (left-hand panel) and population (right-hand panel). Although not all states in the U.S. are represented in the sample, the 48 cities are broadly distributed across more than a half of the continental states, with some states (e.g., TX and NC) having multiple cities. The second column of Table A.2 in the Appendix reports summary statistics for the cities and the selected city-specific characteristics. There is an extensive diversity among the selected cities in terms of the relative city size, measured by average per capita income and population.

Table 2 presents the summary statistics on the magnitude and dispersion of intercity log price differences (left-hand panel) along with its persistence and volatility (right-hand panel) for each product. Not surprisingly, as shown in the first column, there is considerable heterogeneity across products in the average intercity price differences, ranging from 6.0 percent (\#31, MCDONALD HAMBURGER) to 25.7 percent (\#40, NEWSPAPER). In line with the conventional wisdom, intercity price dispersion appears to be smaller for more homogeneous goods, such as GAS and MCDONALD HAMBURGER, than for intrinsically more heterogeneous service products like APARTMENT RENT and BEAUTY SALON. Within each product, a substantive variation is further noticed in the size of citypair price differences. In HOMEPRICE (\#24), for instance, the city-pair price difference varies at a very wide range between merely 3.7 percent and almost 90 percent. Even among relatively homogeneous products such as food products, we notice a nontrivial dispersion of the price disparity: 6.6-77.5 percent for EGGS (\#6) and 7.9-58.5 percent for MARGARINE (\#7), indicative of substantial market segmentation. A large cross-product heterogeneity is also witnessed in the dynamics of intercity price differences. As presented in the right-hand panel of Table 2, the standard deviation of logged price differentials varies significantly across products, between 0.07 for GAS (\#28) and 0.23 for POTATO (\#9). A similar large cross-product variation is witnessed in the persistence of intercity price differences, at the range of 0.53 (for the corresponding half-life of about one quarter) for GAS (\#28) and 0.87 (for the corresponding half-life of around five quarters) for HOMEPRICE (\#24). Overall, the observed large intercity price differences reported in the table indicate that retail price differences across U.S. cities are substantial and persist over time. Product markets are not

manufacturers or retailers, which can distort the effect of arbitrage forces on prices. Third, as pointed out by ER (2001), the ACCRA data may be less rigorous in terms of the sampling methodology and quality of available price data. Refer to ER (2001, p.3) for a further discussion on the limitations of the ACCRA data. 
much integrated across cities even within a national border. What then might potentially explain this heterogeneity across products in the size of the market segmentation? This line of inquiry is pursued in the following section.

\section{Empirical analysis}

In this section, we appeal to a series of regression analyses to explore the role of two frictions in accounting for the observed volatile and persistent movements of intercity price differences. We first conduct a pooling regression analysis by regressing the persistence and volatility of intercity relative prices onto the measures of market friction and nominal rigidity, after controlling for selected cityspecific characteristics, such as real income and city-size differences. We then carry out a group-bygroup regression analysis by dividing the products into several subgroups depending on the degree of price stickiness and tradability to investigate a possible interplay between the two frictions. Here we focus on examining whether and how the strength of marginal effect of market friction changes over the degree of price rigidities and the degree of tradability.

\subsection{Pooling regression analysis}

Determining the main sources of the observed fluctuations of relative prices has been a central issue for both theory and policy. The empirical literature has identified a number of factors contributing to geographic price dispersion, such as variations in transport costs, local trade costs, taxes, and markups which exhibit dispersion across citypairs and products. Whilst none of these factors alone provide a full accounting of the observed dynamics of intercity price differences, special attention has been paid to two factors: transport costs and price stickiness. As a popular metric for transport costs, geographic distance has long been recognized as an important factor behind the price differences between locations. In view of a great deal of empirical evidence that prices are more dissimilar for the location pairs which are geographically farther apart (e.g., Alessandria and Choi forthcoming, Kano et al. 2013) ${ }^{7}$, relative prices are more fluctuating and more persistent between cities located farther apart due to greater transportation costs. Nominal rigidities, typically captured by price stickiness, are also often viewed as an important mechanism capable of generating persistent deviation from the LOP. Standard models with price stickiness and monetary shocks generally predict that nominal

\footnotetext{
${ }^{7}$ Whereas the conventional literature has interpreted this distance effect as solely reflecting transport costs, Choi and Choi (2014) recently maintain that distance contains more information than transport costs.
} 
rigidities lead to large (more volatile) and long lasting (more persistent) deviations in relative prices from the LOP by impeding good prices from adjusting quickly to shocks (e.g., Bergin and Feenstra 2001, Kehoe and Midrigan 2011).

In addition to these two frictions, we consider some city-specific characteristics, such as real per capita income and city population, which are known to have potential explanatory power on price differences between cities. Real income differences are considered in light of the firm link between price and income levels projected in the context of the Harrod-Balassa-Samuelson (HBS) hypothesis and the pricing-to-market (PTM) (e.g., Atkeson and Burstein (2008), Alessandria and Kaboski 2011). ${ }^{8}$ Moreover, real per capita income of a city is conjectured to be closely related to local real wage rates and hence to local distribution costs. Since cities with higher real income level tend to have higher wage rates, real income difference may induce retail price differences through the impact of local costs (e.g., rent). The inclusion of population difference as determinants of intercity price differences comes from our belief that larger markets are likely to have lower markups due to more competitive market environments. This positivity of city size and the degree of competition has been well established in the literature (e.g., Desmet and Parente 2010, Handbury and Weinstein 2014, Melitz and Ottaviano 2008). Melitz and Ottaviano (2008), for instance, documents that difference in city size exerts a significant influence on the relative prices because competitive pressures tend to rise with population size and thus larger markets facing tougher competition have lower average markups. Handbury and Weinstein (2014) also illustrate that the retailer Herfindahl index in selected U.S. cities are negatively correlated with city size, and positively with markups. ${ }^{9}$

We carry out the following pooling regression model in which persistence and volatility of intercity price differences are regressed onto market friction $(M F)$ and nominal rigidity $(N R)$, along with the aforementioned location pair-specific characteristics. The baseline model specification here is similar

\footnotetext{
${ }^{8}$ Although both HBS and PTM predict a positive correlation between income and price, the triggering mechanisms are different between the two. While the HBS hypothesis predicts that the price level of an economy rises with the level of per capita income typically through price differences in the nontradable sector, PTM attributes price differences across economies entirely to tradable goods.

${ }^{9}$ Handbury and Weinstein (2014) maintain that qualitatively similar results are obtained using alternative measures of city size, such as total manufacturing output, due to their high correlation with city population. To the extent that city size difference reflects difference in market competition, it is indirectly related to nominal rigidity in the sense that prices are more rigid in more concentrated (less competitive) markets as claimed by Rotemberg and Saloner (1986).
} 
to the one estimated by CST (2010).

$y_{i j}^{m}=\sum_{h=1}^{N} \gamma_{h} D_{h}^{C}+\sum_{m=1}^{R} \delta_{m} D_{m}^{P}+\beta_{1} M F_{i j}+\beta_{2} N R^{m}+\beta_{3} P O P_{i j}+\beta_{4} R I N C O M E_{i j}+\beta_{5} S A M E S T A T E_{i j}+\varepsilon_{i j}^{m}$.

For the dependent variable $\left(y_{i j}^{m}\right)$, following much of the literature we consider both persistence and volatility of inter-city relative prices which are respectively measured by the sum of the autoregressive coefficients (SARC) and the standard deviation of the log price difference for the $m^{\text {th }}$ good between cities $i$ and $j$ in year $t,\left(\ln P_{i, t}^{m}-\ln P_{j, t}^{m}\right)$. As for the market friction, we use two measures: (1) intercity transport costs estimated by Allen and Arkolakis (forthcoming) which captures the segmentation of goods market; and (2) physical distance which captures the segmentation of both goods and service markets as discussed in Choi and Choi (2014). ${ }^{10}$ For nominal rigidity $\left(N R^{p}\right)$, we utilize the infrequency of price changes measured by the duration of unchanged prices, which is extracted from part of the extensive data set constructed by Nakamura and Steinsson (2008). ${ }^{11}$ Using Table 17 of a supplement to their paper as a guide, where the correspondence between the entry-level items (ELI's) and major product groups are documented, we match the relevant ELI's to 41 of the 45 items in our study. Before proceeding, it should be noted that the measure of market friction (both physical distance and TC) is varying across city-pairs but invariant across products, while the measure of nominal rigidity varies with products only due to the unavailability of data observations at the city level. $D_{h}^{C}$ is a city-pair dummy variable such that the city pair of $\{i, j \in h\}$ would take a value of one. It captures the effect on price differences of other factors than population and real income that are invariant to citypairs. $D_{m}^{P}$ denotes product-specific dummies. ' $P O P$ ' and 'RINCOME' respectively denote city-pair differences in population and real per capita income computed by $\left[\max \left(z_{i}, z_{j}\right)-\min \left(z_{i}, z_{j}\right)\right] / \max \left(z_{i}, z_{j}\right)$ where $z_{k}$ denotes the corresponding variable for city $k$. 'SAMESTATE $E_{i j}$ ' is an intra-state dummy variable which takes one if two cities $i$ and $j$

\footnotetext{
${ }^{10}$ Physical distance between cities $i$ and $j$ is measured by the greater circle formula based on the city's latitude and longitude data, which is the shortest distance between any two points measured along a path on the surface of the sphere. Although the standard practice of probing trade costs has largely involved inferences from the physical distance between locations, price differentials may reflect not only the transport costs but also other factors such as the geographical differences in the local distributional costs and the heterogeneous markups due to a home bias in preferences (e.g., Engel et al. 2003, Choi and Choi 2014).

${ }^{11}$ Nakamura and Steinsson (2008) document the frequency of price changes for non-shelter consumer prices for some 270 entry-level items for the period 1998-2005. All of the products in our list can be matched directly to one of the prices that are compiled by Nakamura and Steinsson, except for the four products, CANNED PEAS, HOME PRICE, MONTHLY PAYMENT, and MAN'S HAIRCUT, which are dropped from our current regression analysis. As shown by Nakamura and Steinsson (2008), the frequency of price change can be transformed to the degree of price stickiness using the formula for implied duration, $d=\frac{-1}{\ln (1-f)}$, where $f$ denotes the frequency of price change. Throughout the paper, we stick to the duration of unchanged prices as our measure of price stickiness.
} 
are in the same state and zero otherwise. Since it controls for the state-specific characteristics like state-tax and policy environment, it is expected to enter with a negative sign because cities in the same state are likely to have similar price levels with more homogeneous tax schemes and economic environments (e.g., industry structure).

Table 3 reports the regression results from pooling the 41 products. Recall that pooling regression analysis is utilized for this exercise due to the availability of nominal rigidity measure at the product level only. The results are supportive of our prior intuition that two frictions are important in explaining the dynamic properties of intercity price differences. As presented in the left-hand panel of Table 3, the pooled regression finds a positive and strongly significant role of the two frictions in explaining the persistence of citypair price differences. The positive coefficients on physical distance and TC indicate that price gap between cities disappears more slowly for the city-pairs that are farther apart, or that have higher transport costs. The quantitative effect of distance on persistence is 0.0177 , implying that a one percent increase in distance between cities leads to an increment of persistence by 0.0177 on average, holding other variables, including nominal rigidity, constant. This result squares well with the conventional wisdom that distance primarily impedes the arbitrage of products by incurring shipping cost. We see a very similar pattern when TC is used as the measure of market friction, although the magnitude of the slope coefficient is much bigger. As expected, nominal rigidity also has a significant positive impact on persistence as the corresponding coefficient $\left(\hat{\beta}_{2}\right)$ is both highly statistically significant and has the expected positive sign, suggesting that intercity price difference disappears more slowly for the products where prices are adjusted less frequently. Quantitatively, a one log-unit rise in price stickiness is associated with almost 0.2 percent increase in persistence.

When it comes to the impact on volatility, however, our exercise yields a somewhat mixed inference on the role of two frictions. As shown in the right-hand panel of Table 3, the two measures of market friction are statistically significant and come out with the expected positive signs, indicating that city-pairs with a higher TC or being farther apart tend to experience more volatile movements in relative prices. A doubling in log distance is associated with an almost one percent increase in volatility. By stark contrast, the coefficient on nominal rigidity is statistically significant but with an unexpected negative sign. This pattern holds regardless of the measure of market friction adopted. To put it another way, intercity price gap fluctuates less for products that change prices less frequently. This is at odds with the predictions of standard models with sticky prices (e.g., New Key- 
nesian models) that volatility of LOP deviations rises with the degree of price rigidity in the presence of monetary shocks (e.g., Carvalho and Nechio 2011). Our result, however, corroborates the recent empirical findings based on micro price data by Kehoe and Midrigan (2011) and CST (2010) that stickier-priced goods exhibit a more persistent but not necessarily more volatile movement in relative prices. Using retail prices of Japanese cities, for example, CST (2010) find that products exhibiting a greater degree of price stickiness tend to present less variation in intercity relative prices, which runs a counter to the prediction of their own two-country monetary model based on Calvo-type price stickiness.

The dynamic properties of intercity price wedges are also explained by the aforementioned citylevel characteristics. With the exception of real income difference which takes a counter-intuitive negative sign for persistence, all the location pair-specific regressors enter significantly with the anticipated signs. Population difference is statistically significant in explaining the volatility and persistence of intercity price gaps. The positive coefficient on population difference indicates that citypairs with a larger difference in city-size systematically experience more persistent and more volatile movements of price differences. This may reflect markup differences across cities owing to different market sizes, or differences in local wages and distribution costs which depend to a greater extent on city-size. By contrast, the 'RINCOME' variable, or differences in real income per capita, is significant for volatility but have little explanatory power for persistence. In view of the fact that real income is an important mechanism through which the practice of PTM explains price differences across cities, our result on the limited significance of real income differences weighs against the relevance of the PTM argument at least to the U.S. cities under study. Our finding, however, is congruent with the recent IO literature (e.g., Ellickson and Misra 2008) that retailers rarely exercise market power in their pricing decision. The coefficient on the 'SAMESTATE' dummy variable is of the anticipated negative sign and highly significant. This suggests that the persistence and volatility of price differences for city-pairs which lie across the state border are greater than those lie within the same states, after controlling for the two frictions and other explanatory variables.

To sum, our pooling regression results point a lack of coherence between theory and empirical evidence on price stickiness. Our empirical evidence suggests differently from what is predicted by standard theoretical models regarding the role of price stickiness. 


\subsection{Interplay of the two frictions}

Our analysis so far verifies the significant role played by the two frictions in accounting for the dynamic properties of inter-city relative prices. The outcomes, however, are not informative about the potential interplay between the two frictions. In an economy with nominal rigidities that hinder prices from adjusting quickly, monetary or real shocks are known to trigger larger and more persistent movements of relative prices between two cities that are farther apart. What is less known is about whether and how the strength of the impact of market friction is associated with the extent of nominal rigidity. As emphasized by ER $(1996,2001)$, a successful theoretical explanation for stochastic behavior of relative prices should incorporate both transport costs (market friction) and price stickiness (nominal rigidity). ${ }^{12}$ Inspired by this, the current section elaborates on the potential interactions between market friction and nominal rigidity in explaining the observed persistence and volatility of inter-city price differences. Specifically we address the question of whether and how the magnitude of the impact of market friction varies over the degree of nominal rigidities.

To make our framework suitable for addressing this question, we conduct a group-by-group regression analysis in which all the 41 products are partitioned into three large categories based on the degree of price stickiness: highly-sticky (H), medium-sticky (M), and low-sticky (L). Although it is not straightforward to draw dividing lines among the three groups as highlighted by Choi and O'Sullivan (2013), we use 6 months and 12 months as reasonable separating points. In consequence, as summarized in Table A.1, we have 11 products belonging to the highly-sticky group whose prices are set for more than one year at a time, 12 products in the low-sticky price group whose prices are set less than for six months at a time, and the remaining 18 products included in the medium-sticky price group. So far as more flexibly priced products have a lower persistence of intercity relative prices due to a quicker response to shocks, on a priori grounds one may expect that the marginal effect of market friction on the persistence and volatility is smaller in the low-sticky price group.

We perform the following regression analysis to evaluate the marginal impact of market friction in the three subgroups based on price stickiness,

$$
y_{i j}^{g p}=\gamma M F_{i j}+X \beta+\varepsilon_{i j}^{p}, \quad \text { where } g=1,2,3
$$

where the superscript 'g' denotes an observation on three product groups. As before, $y_{i j}^{g p}$ represents the persistence and volatility of price differentials between cities $i$ and $j$ for the product

\footnotetext{
${ }^{12}$ In the context of optimal inflation, Wolman (2011) also highlights the importance of the interactions between transactions frictions and price stickiness as sources of the nonneutrality of money.
} 
group $g$, and $M F_{i j}$ denotes market friction (log distance and transport costs) for the city-pair of $i$ and $j$. In this specification, $\gamma$ is the parameter of our central interest as it tells us how the strength of the marginal effect of market friction varies across the three subgroups. $X=$ $\left\{R I N C O M E_{i j}, P O P_{i j}, S A M E S T A T E_{i j}, D^{p}, D_{i}^{C}, D_{j}^{C}\right\}$ is a vector of the other explanatory variables discussed earlier and their description remains the same as in the previous section.

The upper panel of Table 4 presents the results of this exercise. Again, we conduct four sets of regression exercises with two dependent variables, persistence and volatility of intercity price differences, for two different measures of market friction, log distance and TC. The results are very similar to those outlined above, clearly demonstrating the explanatory power of market friction. In all cases but one, the coefficients on log distance and TC $(\hat{\gamma})$ remain positive and significant. This ascertains our conclusion from the pooling regression analysis that volatility and persistence of intercity price differentials rise with distance and TC between cities. What is more interesting is that the quantitative effect of market friction varies significantly across the three product groups based on price stickiness. To be specific, the strength of the marginal effect of market friction appears to decrease with the extent of price rigidity. The marginal effect is the strongest in the low-sticky price group where prices are adjusted most flexibly, while it is the weakest in the high-sticky price group. In the quantitative sense, the marginal effect of market friction is four to eight times stronger in the low-sticky price group compared to the high-sticky price group. That is, a doubling in log distance or TC is associated with an increase in the persistence and volatility of intercity price differences by 4 to 8 times more in the flexible price products compared to the sticky price products. At first glance, this result seems somewhat counter-intuitive in light of the popular view that price rigidity would strengthen the marginal effect of market friction because it is known to generate persistent and volatile movements of relative prices typically by impeding good prices from adjusting quickly. ${ }^{13}$ Our result, however, can still be reconciled with the common view because it is not about the effect of price rigidity per se, but about the marginal effect of market friction with respect to the degree of price rigidity. Volatility and persistence of intercity relative prices rise with the degree of market segmentation as generally believed, but their sensitivities to market friction tend to decline with the extent of price stickiness. This is because in more flexible price products where firms can change prices more frequently, pass-through from changes in marginal costs to retail price will be in general

\footnotetext{
${ }^{13}$ This also runs counter to the popular belief on the positive relationship between market friction and nominal rigidity (i.e., firms price less frequently for the markets that are farther apart).
} 
larger. When markets are segmented by distance or TC, however, the pass-through of price changes to other cities will be limited and hence price gaps between markets are likely to be large and longlasting. If prices are less synchronized due to market friction, more frequent price adjustments in each market would give rise to a more volatile and more persistent movements of relative prices across cities.

That market friction has a greater impact on the products with a lower price stickiness is conceptually related to the controversial finding by ER (2001) that variability of relative prices is larger for traded goods whose prices are in general more flexibly adjusted. Using disaggregated consumer price data for U.S. cities, ER (2001) find that deviations from the proportional LOP (PLOP) are larger for traded goods than nontraded goods. This observation casts doubt on the empirical validity of the prediction of conventional trade theory that LOP holds for traded goods but not non-traded goods. Interestingly, the authors ascribe their finding to a lower price stickiness of traded goods, with an implicit implication on the inverse relationship between price stickiness and tradability. We view that our results in this section can shed some light on their finding. To the extent that a close inverse relationship exists between nominal rigidity and tradability possibly through market structure $^{14}$, prices in tradable goods are adjusted more frequently compared to their nontradable counterparts and thus they are likely to have a stronger marginal impact of market friction. In this context, tradable goods could have more volatile and more persistent movements of relative prices for a given level of market friction.

To illuminate this issue, we utilize the data compiled by Crucini and Shintani (2008) on distribution margins for various goods and services in the U.S. Based on the difference between what final consumers pay and what producers receive, which encompasses all the real costs associated with the movement of goods and services from producers to consumers plus markups over marginal cost, the distribution margins can be viewed as the inverse measure of tradability of the good in question, which takes a value of zero in case of perfect tradability and a value of one in the case of complete nontradabilty (Crucini and Shintani 2008, p.632). We could match all of the 45 products under study to their raw dataset. To get a sense of its relevance, Figure 2 plots the relationship between the distribution margin of each product against the degree of price stickiness. A clear upward sloping relationship in Figure 2 conforms to our initial intuition that less tradable products with a larger

\footnotetext{
${ }^{14}$ Tradable products are likely produced in a more competitive market environment, possibly due to a larger number of competitors in a broader market. Market structure in turn has an implication on the nominal rigidity in that more monopolistic firms can set prices less frequently.
} 
distribution margin tend to have stickier price adjustments.

Drawing on the approach of Crucini and Shintani, we implement another group-by-group regression analysis to investigate how the marginal impact of market friction would change over different groups in terms of distribution margin, or non-tradability. We divide the 45 products into two subgroups with the separating point of distribution margin value being equal to 0.5 - a more-tradable product group for the distribution margin value less than 0.5. As reported in the lower panel of Table 4, the coefficient on market friction remains positive and significant in all cased considered. As anticipated, the strength of marginal effect of market friction differs substantively between the two subgroups. It is much larger in the more-tradable product groups, implying that marginal impact of the market friction on persistence and volatility is stronger for more tradable products whose prices are more frequently adjusted. Our result can be interpreted as saying that market segmentation by distance or TC causes a more volatile and more persistent price differences in the products that are more tradable.

The central assertion in this section is that the strength of the marginal effect of market friction hinges on the extent of nominal rigidity, but not in a reinforcing manner as often assumed in the literature. The strength of marginal effect of market friction is in fact inversely associated with the degree of nominal rigidity. Dynamics of intercity price gaps are more responsive to market segmentation by distance or TC for the products whose prices are adjusted more frequently and are more tradable.

\section{The Model}

In this section, we develop a model which can explain the dynamic properties of relative prices for goods across U.S. cities. We extend the state-dependent pricing model in Dotsey et al. (1999) to a symmetric two-city model with market frictions to endogenize the pricing behavior of producers. By so doing, we can analyze explicitly the different roles of market friction and nominal rigidities on the relative price dynamics.

\subsection{Two City Model}

The economy consists of two cities indexed $i \in\{1,2\}$ within a country. Each city is populated by a continuum of identical consumers who buy goods from firms in two cities and supply labor, $L_{i, t}$, to firms in their cities. Consumers in both cities have access to a complete set of state contingent 
securities denominated in the country's currency. In the economy there are a continuum of goods indexed $g \in[0,1]$. For each good, there are a continuum of brands indexed $(i, g, v)$ with the index of brand $v \in[0,1] .^{15}$ Each brand is produced by one firm which sells its product in two cities under the monopolistically competitive market environment. The production function of each firm is given as $Y_{t}(i, g, v)=Z_{t}(i, g) L_{t}(i, g, v)$, where $Y_{t}(i, g, v)$ and $L_{t}(i, g, v)$ are the output and the labor input of firm $(i, g, v)$, respectively, and $Z_{t}(i, g)$ is the city and good specific productivity. The productivity follows an $\mathrm{AR}(1)$ process with $\ln Z_{t}(i, g)=\rho_{z} \ln Z_{t-1}(i, g)+\varepsilon_{t}^{z}(i, g)$, where $\varepsilon_{t}^{z}(i, g)$ is the idiosyncratic shock to productivity with $\varepsilon_{t}^{z}(i, g) \stackrel{i i d}{\sim} N\left(0, \sigma_{z}^{2}\right)$. The demand for each brand is derived from a CES aggregate over brands,

$$
C_{i, t}(g)=\left(\sum_{k=1}^{2} \int_{0}^{1} C_{i, t}(k, g, v)^{\frac{\theta-1}{\theta}} d v\right)^{\frac{\theta}{\theta-1}}
$$

where $\theta>1$ is the elasticity of substitution, $C_{i, t}(g)$ is city $i$ 's demand for good $g$, and $C_{i, t}(k, g, v)$ is city $i$ 's demand for brand $v$ of good $g$ produced in city $k$. The price index of good $g$ in city $i$ is given as $P_{i, t}(g)=\left(\sum_{k=1}^{2} \int_{0}^{1} P_{i, t}(k, g, v)^{1-\theta} d v\right)^{\frac{1}{1-\theta}}$, where $P_{i, t}(k, g, v)$ is the price in city $i$ for brand $v$ of good $g$ produced in city $k$.

The consumers in city $i$ have the expected lifetime utility of $E_{0} \sum_{t=0}^{\infty} \beta^{t}\left(\ln C_{i, t}-L_{i, t}\right)$, where $E_{0}$ is the conditional expectation operator, $\beta \in(0,1)$ is the subjective time discount factor, and $C_{i, t}$ is the aggregate consumption of goods in city $i$ defined as $\ln C_{i, t}=\int_{0}^{1} \ln C_{i, t}(g) d g$. The consumers face the cash-in-advance constraint, $M_{i, t} \geq P_{i, t} C_{i, t}$, where $M_{i, t}$ is the money supply in city $i$, and $P_{i, t}$ is the price index of the city $i, \ln P_{i, t}=\int_{0}^{1} \ln P_{i, t}(g) d g$. The money supply in a city is given as $\ln M_{i, t}=\mu t+m_{t}$ with $m_{t}=\rho_{m} m_{t-1}+\varepsilon_{t}^{m}$, where $\mu>0$ is the trend, $\rho_{m} \geq 0$ is the persistence of money supply, and $\varepsilon_{t}^{m}$ is the idiosyncratic shock to money supply which is common across cities with $\varepsilon_{t}^{m} \stackrel{i i d}{\sim} N\left(0, \sigma_{m}^{2}\right) \cdot{ }^{16}$ The solutions to the consumer's problem give $C_{i, t}=W_{i, t} / P_{i, t}$, where $W_{i, t}$ is the wage rate in city $i$. In an equilibrium with the utility function and the cash-in-advance constraint we have $W_{i, t}=M_{i, t}$.

There are two types of frictions in the economy. First, there are heterogeneous market frictions across goods because selling a brand in the other city is costly. A firm has to pay for the marginal trade cost of $\tau_{g} \geq 0$ to sell its product in the other city (e.g, Alessandria and Choi 2007). This marginal trade cost may vary across goods. The second friction is the nominal rigidity. Firms set

\footnotetext{
${ }^{15}$ With producers in two cities, the total mass of brands for a good is 2 .

${ }^{16}$ Under the complete asset market condition, having different money supplies in two cities does not alter the results.
} 
their prices infrequently due to a fixed price adjustment cost. When a firm producing brand $v$ of good $g$ in city $i$ resets its price, it has to pay the fixed price adjustment cost of $f_{g} \xi$ measured in labor units. Here, $f_{g}>0$ is common across cities but specific to goods, and $\xi$ is an i.i.d. random shock that each firm receives in each period. The shock is drawn from a common c.d.f. function $G(\xi)$ with $\xi \in(0,1)$. Upon the payment of the cost, the firm can change its prices in all markets. With a positive inflation rate in the country, $\mu>0$, firms producing a brand of good $g$ in city $i$ change their prices at least once within $J(i, g)$ periods. Due to the fixed price adjustment cost, in each period there is a fraction of firms that set their prices $j$ periods ago, $\omega_{j, t}(i, g), j=0,1,2, \ldots, J(i, g)-1$. Using the fraction of firms $\omega_{j, t}(i, g)$, we can rewrite the price index of good $g$ in city $i$ as

$$
P_{i, t}(g)=\left[\sum_{k=1}^{2} \sum_{j=0}^{J(k, g)-1} \omega_{j, t}(k, g) P_{i, t-j}^{*}(k, g)^{1-\theta}\right]^{\frac{1}{1-\theta}}
$$

where $P_{i, t-j}^{*}(k, g)$ is the price in city $i$ set $j$ periods ago by a firm producing a brand of good $g$ in city $k .^{17}$

\subsection{Persistence and Volatility of the Relative Price}

Before moving to the simulation exercise, several points are worth noting regarding the dynamics of intercity relative prices. The main departure of the model from an exogenous price resetting model, e.g., Calvo pricing or staggered pricing models, is that the probability of price resetting is endogenous and time varying with the presence of fixed price adjustment cost. In an extreme case with a Bernoulli distribution for $\xi$ with $\operatorname{Pr}(\xi=1)=\lambda$ and $f_{g} \rightarrow \infty$, the model collapses to a Calvo pricing model. In this case, as shown by CST (2010) the price dynamics becomes

$$
q_{i j, t}=\lambda q_{i j, t-1}+\frac{(1-\lambda)(1-\lambda \beta)}{1-\lambda \beta \rho_{z}}\left(2 s_{i j}-1\right) z_{i j, t},
$$

where $q_{i j, t}=\ln \left(P_{i, t} / P_{j, t}\right), s_{i j}=1 /\left[1+(1+\tau)^{1-\theta}\right]>1 / 2$ measures the home bias, and $z_{i j, t}=$ $\ln \left(Z_{i, t} / Z_{j, t}\right) .{ }^{18}$ If $\lambda=0$, the prices are fully flexible. In this case, the persistence of the relative price, $q$, is equal to the persistence of productivity, and the (conditional) volatility of $q$ is increasing in $\tau$ and $\rho_{z}$. If $\lambda>0$, the persistence is given by $\left(\lambda+\rho_{z}\right) /\left(1+\lambda \rho_{z}\right)$ which is increasing in $\lambda$ but is independent of $\tau$. The (conditional) volatility is increasing in $\tau$ but is decreasing in $\lambda$. So, the Calvo

\footnotetext{
${ }^{17}$ See Appendix B for the detailed model setup and solutions.

${ }^{18}$ Here we drop the good index for notational convenience.
} 
pricing model as in CST (2010) is unable to explain the positive relationship between the persistence of $q$ and the marginal trade cost.

By contrast, in our model the market friction $(\tau)$ affects both the persistence and volatility of relative price through a couple of channels. First, the profit of a firm is decreasing in the market friction, even though the market share of a good is invariant to the market friction $\left(\tau_{g}\right)$ with the Cobb-Douglas aggregate over goods. In turn, the market friction affects pricing decisions and the fraction of price-changing firms $(\omega)$ which ultimately affect the persistence and volatility of the relative price in two cities even if the nominal friction $\left(f_{g}\right)$ is invariant across goods. Second, the nominal rigidity directly affects the pricing decisions. The higher the nominal rigidity $\left(f_{g}\right)$ is, the lower is the incentive for firms to reset prices. So, the frequency of price resetting and $\omega$ are directly influenced by the nominal rigidity and hence change the dynamics of relative price. The distribution of $\xi$ is crucial for the magnitude of the impacts of $\tau$ and $f_{g}$ on the persistence and volatility of relative price. Similar to the Calvo pricing case, the persistence of relative price is primarily determined by the persistence of the productivity for the frequently price-adjusting firms, whereas the persistence for the infrequently price-adjusting firms is primarily determined by the duration of the unchanged prices. If the fraction of frequent price changers is high (low) among all the price changers in a given period, a fall in the average frequency of price change with a higher market friction will have a relatively small (big) impact on the persistence. Thus, a left-skewed distribution of $\xi$ as in Dotsey et al. (1999) is essential for the size of the effect of the market friction on the persistence of the relative price.

\subsection{Simulation Exercise}

To examine how our model matches the key features of the data, we carry out a series of simulation exercise in which the parameter values are set based on quarterly frequency. The time discount factor is set to be 0.99 , or $\beta=0.99$, and the elasticity of substitution $(\theta)$ is set as 4 . We set the persistence and volatility of productivity to be $\rho_{z}=0.95$ and $\sigma_{z}=0.007$ with $\operatorname{Corr}\left(\varepsilon_{t}^{z}(1, g), \varepsilon_{t}^{z}(2, g)\right)=0$. The parameter values for the money supply are set as $\mu=0.03 / 4, \rho_{m}=0.95$, and $\sigma_{m}=0.005$. The fixed cost parameters are chosen on the basis of the good with zero marginal trade cost which is equivalent to a one-city model. ${ }^{19}$ Specifically, the fixed cost parameters are set to get: (i) the frequency of price change is 0.20 as in Kehoe and Midrigan (2011) and Midrigan (2010); (ii) firms change their

\footnotetext{
${ }^{19}$ Alternatively, we may use a positive marginal trade cost for the calibration. The results are unaltered when a positive marginal cost is used in the calibration.
} 
prices at least once within 6 periods $J=6$ with 3 percent annual inflation rate as in Dotsey et al. (1999). Similar to Dotsey et al. (1999), we use a distribution of the price adjustment cost shock which is skewed to the left. To this end, we use a beta distribution for $\xi, \operatorname{Beta}(a, b)$, with $b=1$ and calibrate $a$ and $f_{g}$ to get the frequency of price adjustment of 0.20 with $J=6 .{ }^{20}$ This gives $a=5$ and $f_{g}=\bar{f}=0.023$. We assume that the nominal rigidity and market friction, $f_{g}$ and $\tau_{g}$, are distributed with a joint p.d.f. of $\psi\left(f_{g}, \tau_{g}\right) .{ }^{21}$ The model is simulated based on log-linearization as in Dotsey et al. (1999).

We first examine the effects of market friction on the persistence and volatility of citypair relative prices. We collect the relative prices of goods $\widehat{p}_{g, t}=\ln \left(P_{2, t}(g) / P_{1, t}(g)\right)$ with the same value of $f_{g}$, but with various market frictions $\left(\tau_{g}\right)$ in the model. The persistence and the conditional volatility of $\widehat{p}_{g, t}$ are defined as the $\operatorname{AR}(1)$ coefficient of $\widehat{p}_{g, t}$ and the volatility of the residual, respectively. The unconditional volatility is defined as the standard deviation of $\widehat{p}_{g, t}, \operatorname{std}\left(\widehat{p}_{g, t}\right)$. The model statistics are obtained as the mean of the statistics from 2,000 iterations with 200 periods. The left-hand panel of Figure 3 exhibits the persistence, and conditional and unconditional volatilities of intercity relative prices for various values of the market friction, $\tau_{g}$, but with the same nominal rigidity, $f_{g}=\bar{f}$. The simulation results show that not only the conditional and unconditional volatilities, but also persistence increase with the market friction $\left(\tau_{g}\right)$ as observed in the data. This is quite different from the predictions from a Calvo pricing model. As discussed in CST (2010, 2012), a standard two-city Calvo pricing model cannot replicate the positive relationship between persistence and market friction. In the Calvo pricing model, the volatility of relative price is shown to rise with market friction, but persistence, which is the exogenous probability of keeping the same prices for a firm, falls with it.

In contrast, as displayed in the left-hand panel of Figure 3, our model predicts a positive relationship between persistence and volatility against market friction. This is because in our model market friction has two distinctive impacts on the dynamics of relative prices resulting from the endogeneity of the probability of resetting price. First, market friction affects the volatility directly. With a greater market friction, firm's newly set relative price rises with the market friction. At the same time, market friction affects the persistence directly and the volatility indirectly. With a

\footnotetext{
${ }^{20}$ We set $a>1$ and $b=1$ so that the distribution of $\xi$ is left-skewed and the pdf is increasing in $\xi$ in the right tail of the distribution as in Dotsey et al. (1999).

${ }^{21}$ Since a good's market is independent from the other goods' markets with the Cobb-Douglas aggregate over goods, the simulation results are independent of the specification of the distribution, $\psi\left(f_{g}, \tau_{g}\right)$.
} 
greater market friction, firms have less incentives to change their prices in the presence of fixed price adjustment cost because the profits in the other city decline with the market friction. This leads to a higher persistence for the intercity price difference. Even though the volatility falls with the persistence given the market friction as discussed in CST (2010), the direct effect on the volatility outweighs the indirect effect via the persistence, resulting in a positive comovement between volatility and persistence with respect to the change in market friction.

To investigate the role of nominal rigidity on the dynamics of the relative price, we collect the simulated relative prices of goods for which the market frictions are the same at $\tau_{g}=0.10$ but with different nominal frictions, $f_{g}$. The right-hand panel of Figure 3 displays the volatility and persistence across different nominal frictions relative to the case with $f_{g}=\bar{f}$. As shown in the figure, our model predicts that conditional and unconditional volatilities decline with the extent of nominal rigidity, while persistence rises with it. This is what we observed from the data. Since firms with a higher nominal rigidity have less incentives to change prices, the persistence of intercity price difference increases with the degree of nominal rigidity, which also affects the volatility indirectly. With a smaller percentage of firms that change their prices, the volatility falls with nominal friction. Consequently, as discussed in CST (2010), given the level of market friction, volatility moves in the opposite direction with persistence in response to a change in nominal rigidity.

Figure 4 shows the interplay of market friction and nominal rigidity by looking at marginal effects of the market friction for various frequencies of price adjustments. We select the nominal frictions $f_{g}$ so that the frequency of price changes are in the range of $[0.15,0.20]$ with the market friction of $\tau_{g}=0.10$. Then, we vary $\tau_{g}$ for each $f_{g}$. As shown in panel (a), the conditional volatility is increasing with the extent of nominal rigidity for given market friction $\tau$. More importantly, the marginal effect of market friction $(\tau)$ is increasing in the frequency of price changes, i.e., a higher frequency of price adjustments, or a lower nominal rigidity, leads to a higher marginal effect of market friction $(\tau)$ on the conditional volatility. This is because when many firms change their prices with a high frequency of price changes, the volatility becomes relatively high. Panel (c) of Figure 4 illustrates that persistence is decreasing in the frequency of price adjustment, while marginal effect of the market friction is increasing in the frequency. The inverse relationship between persistence and nominal rigidity is a direct consequence of the positive effect of duration of unchanged prices on persistence. The marginal effect of the market friction on persistence, however, is quite different. Persistence is already high when the frequency of price adjustments is low and hence a marginal 
increase in the market friction $(\tau)$ would diminish with the frequency of price adjustments. The overall effect on persistence is relatively less influenced by the change in market friction. As one can see from Panel (b) of Figure 4, marginal effect of the market friction $(\tau)$ on the unconditional volatility is quite mixed because the marginal effect of $\tau$ on the conditional volatility is rising with the frequency, whereas its impact on persistence is decreasing with the frequency. Consequently, the marginal effect of $\tau$ on the unconditional volatility hinges on the relative dominance between the two opposing effects as it can either increase or decrease in the frequency of price adjustments. ${ }^{22}$

\section{Concluding remarks}

It is widely documented that price difference across locations is large and persistent even within a national border. This paper contributes to the empirical evidence and the theoretical development on the magnitude and determinants of intercity price differences in the U.S. by exploring the role of two frictions that are often studied in the literature: (1) market friction arising from market segmentation due to physical distance or TC; and (2) nominal rigidity due to sluggish price adjustments. A theoretical and empirical exploration of this issue is provided here in order to delve into the roles of the two frictions on the dynamic behavior of intercity price wedges. Using the retail price dataset of 45 goods and service in 48 U.S. cities, we could verify the extant literature that these two frictions can explain a significant amount of the variation in the spatial price dispersion. Our empirical results, however, do not give much support to standard theoretical models that typically predict a positive association between nominal rigidity and volatility of relative prices. In an attempt to bridge the gap between theory and data, we propose an alternative theoretical explanation for the empirical evidence within the setting of the state-dependent model by Dotsey et al. (1999).

We extend our analysis to investigate the interplay of the two frictions in explaining the observed dynamics of good-level inter-city price differences, which has been largely overlooked in the literature. Although considerable progress has been made in understanding the dynamic properties of relative prices using micro data, not much is known about how the two frictions interact each other in creating the large and long-lasting fluctuations observed in price differences across locations. Our focus here rests on addressing the question of how the impact of market friction varies over the extent of nominal rigidity. The intuition behind this is that so long as the dynamics of relative prices involve

\footnotetext{
${ }^{22}$ We are cautious about the statement of the marginal effects with respect to the frequency of price adjustments. Due to the discrete nature of the maximum duration of prices, $J$, and the negative relationship between the long-term persistence of productivity and the length of the time periods, the responses are not globally monotonic.
} 
multiple frictions through mechanisms that could be either amplified or offset by each other, a richer understanding of the dynamic properties of relative prices can be achieved by looking at how one friction interacts with the other. We find that marginal effect of the market friction is dependent on nominal rigidities in such a way that the strength of marginal effect diminishes with the extent of price stickiness increases. Simply put, it is not in the most sticky price group, but in the most flexible price group, where the marginal effect of market friction is the strongest. This result seems at odds with the conventional wisdom that nominal frictions lead to large (more volatile) and long lasting (more persistent) deviations in relative prices from the LOP by preventing good prices from adjusting quickly to shocks. But, even when firms in flexible price sectors can pass through marginal costs to retail price more frequently, price adjustments could be less synchronized across cities if markets are segmented by distance or TC. This is how nominal rigidity interacts with market friction in affecting price differences across locations. Highly flexible price adjustments in two segmented markets can therefore give rise to more persistent and more volatile movements in intercity relative prices. This novel empirical regularity can be produced by our two-city model based on state-dependent pricing in which the persistence and volatility of intercity relative prices depend explicitly on the frequency of price adjustments in the product. 


\section{References}

[1] Alessandria, George and Horag Choi (2007): "Do Sunk Costs of Exporting Matter for Net Export Dynamics?" Quarterly Journal of Economics, 122(1), 289-336.

[2] Alessandria, George and Horag Choi (forthcoming): "Do Falling Iceberg Costs Explain Recent U.S. Export Growth?" Journal of International Economics.

[3] Alessandria, George and Joseph P. Kaboski (2011): "Pricing-to-Market and the Failure of Absolute PPP," American Economic Journal: Macroeconomics, 3, 91-127.

[4] Allen, Treb and Costas Arkolakis (forthcoming): "Trade and the Topography of the Spatial Economy," Quarterly Journal of Economics.

[5] American Chamber of Commerce Researchers Association. Intercity Cost of Living Index, Quarterly Reports, 1976- 2009.

[6] Anderson, James E. and Eric van Wincoop (2004): "Trade Costs," Journal of Economic Literature, XLII, 691-751.

[7] Atkeson, Andrew and Ariel Burstein (2008): "Pricing to Market, Trade Costs, and International Relative Prices," American Economic Review, 98(5), 1998-2031.

[8] Bergin, Paul and Robert C. Feenstra (2001): "Pricing to Market, Staggered Contracts, and Real Exchange Rate Persistence," Journal of International Economics, 54(2), 333-359.

[9] Bils, Mark and Peter J. Klenow (2004): "Some evidence on the importance of sticky prices," Journal of Political Economy 112, 947-985.

[10] Carvalho, Carlos and Fernanda Nechio (2011): "Aggregation and the PPP Puzzle in a StickyPrice Model," American Economic Review, 101, 2391-2424.

[11] Choi, Chi-Young and Horag Choi (2014): "Does Distance Reflect More Than Transport Costs?" Economics Letters, 125(1), 82-86.

[12] Choi, Chi-Young, Nelson C. Mark and Donggyu Sul (2006): "Unbiased estimation of the half-life to PPP convergence in panel data," Journal Money, Credit and Banking, 38(4), 921-938.

[13] Choi, Chi-Young and Róisín O'Sullivan (2013): "Heterogeneous Response of Disaggregate Inflation to Monetary Policy Regime Change: The Role of Price Stickiness," Journal of Economic Dynamics and Control, 37(9), 1814-1832.

[14] Crucini, Mario J. and Mototsugu Shintani (2008): "Persistence in law of one price deviations: Evidence from micro-data," Journal of Monetary Economics, 55, 629-644.

[15] Crucini, Mario J., Mototsugu Shintani and Takayuki Tsuruga (2010): "The Law of One Price without the Border: The Role of Distance Versus Sticky Prices," Economic Journal, 120, 462480 .

[16] Crucini, Mario J., Mototsugu Shintani and Takayuki Tsuruga (2012): "Noisy information, distance and law of one price dynamics across US cities," NBER Working Papers No. 17815, National Bureau of Economic Research.

[17] Desmet, Klaus and Stephen Parente (2010: "Bigger is Better: Market Size, Demand Elasticity and Innovation," International Economic Review, 51(2), 319-333.

[18] Dotsey, Michael, Robert G. King, and Alexander L. Wolman (1999): "State-Dependent Pricing And The General Equilibrium Dynamics Of Money And Output," The Quarterly Journal of Economics, 114(2), 655-690. 
[19] Dornbusch, Rudiger (1976): "Expectations and Exchange Rate Dynamics," Journal of Political Economy, 84(6), 1161-1176.

[20] Ellickson, Paul B. and Sanjog Misra (2008): "Supermarket pricing strategies," Marketing Science, 27(5), 811-828.

[21] Engel, Charles (1999): “Accounting for U.S. real exchange rate changes," Journal of Political Economy, 107(3), 507-538.

[22] Engel, Charles and John H. Rogers (1996): "How Wide Is the Border?," American Economic Review, 86(5), 1112-25.

[23] Engel, Charles and John H. Rogers (2001): "Violating the Law of One Price: Should We Make a Federal Case Out of It?," Journal of Money, Credit, and Banking, 33(1), 1-15.

[24] Engel, Charles, Rogers, John .H., and S.-Y. Wang (2003): "Revisiting the Border: An Assessment of the Law of One Price Using Very Disaggregated Consumer Price Data". International Finance Discussion Papers No. 777, Board of Governors of the Federal Reserve System.

[25] Handbury, Jessie and David E. Weinstein (forthcoming): "Goods Prices and Availability in Cities," Review of Economic Studies.

[26] Kano, Kazuko, Kano, Takashi, and Kazutaka Takechi (2013): "Exaggerated death of distance: Revisiting distance effects on regional price dispersions," Journal of International Economics, 90, 403-413.

[27] Kehoe, Patrick J. and Virgiliu Midrigan (2011): "The Puzzling Behavior of Sectoral Real Exchange Rates," Federal Reserve Bank of Minneapolis Working Paper, No. 656.

[28] Melitz, Marc J. and Gianmarco I.P. Ottaviano (2008): "Market Size, Trade, and Productivity," Review of Economic Studies, 75(3), 985-985.

[29] Midrigan, Virgiliu (2010): "Is Firm Pricing State or Time Dependent? Evidence from US Manufacturing," Review of Economics and Statistics, 92(3), 643Ü656.

[30] Nakamura, Emi and Jón Steinsson (2008): "Five facts about prices: A reevaluation of menu cost models," Quarterly Journal of Economics, 123, 1415-64.

[31] O'Connell, Paul G.J. and Shang-Jin Wei (2002): "The bigger they are, the harder they fall": Retail price differences across U.S. cities," Journal of International Economics, 56(1), 21-53.

[32] Parsley, David C. and Shang-Jin Wei (1996): "Convergence to the Law of One Price Without Trade Barriers or Currency Fluctuations," Quarterly Journal of Economics, 111, 1211-1236.

[33] Rogoff, Kenneth (1996): "The purchasing power parity puzzle," Journal Economic Literature, $34(2), 647-668$.

[34] Rotemberg, Julio J. and Garth Saloner (1986): "A Supergame-Theoretic Model of Price Wars during Booms," American Economic Review, 76(3), 390-407.

[35] Taylor, Alan M. (2001): "Potential pitfalls for the PPP puzzle? Sampling and specification biases in mean-reversion tests of the law of one price," Econometrica 69(2), 473-498.

[36] Wolman, Alexander L. (2011): "The Optimal Rate of Inflation with Trending Relative Prices," Journal of Money, Credit and Banking, 43(2-3), 355-384. 


\section{Appendix}

\section{A Data Description}

Our data set comprises actual retail prices of individual goods and services collected from the American Chamber of Commerce Researchers Association (ACCRA) publication, Cost of Living Index, which was also employed by some previous studies on a similar line of research (e.g., Parsley and Wei 1996, O'Connell and Wei 2002, CST 2012). The survey data are available every quarter since 1968.Q1 when prices were first recorded for 44 items in 113 cities and have been subsequently extended to embrace a maximum of 756 locations and 75 consumer products by the end of 2009. Due to frequent revisions in the coverage of cities and products, however, the time series data have occasional missing observations. We follow Parsley and Wei (1996, p.1213-15) and O'Connell and Wei (2002, p.35-6) to linearly interpolate missing values in constructing the dataset. A missing observation that is not continuous is therefore replaced with the centered two-quarter average value. Our conclusions are virtually unaltered by using nonlinear interpolation methods. After dropping any series that have missing observations for more than two consecutive quarters, we end up with the sample of 51 cities that appeared in roughly 90 percent of the quarterly surveys for 45 goods and services between 1985.Q1 and 2009.Q4. A clear trade-off exists between data span and data coverage as the number of cities with available data reduces dramatically to 22 if we start the sample from 1976 . Since the focus of our study lies in the cross-product heterogeneity of inter-city relative prices, we choose the breadth of coverage in terms of available cities and products over the length of time. Another important motivation for focusing on the post-1985 data is to minimize the nontrivial influence of the so-called Great Inflation on the stochastic properties of individual good prices in the U.S. intercity relative prices might have experienced structural breaks at the onset of the Great Moderation possibly through the change in nominal rigidities.

\section{B Model Solution}

In this appendix, we present the model solutions for the pricing rules and price indices.

\section{B.1 Consumer's Problem}

The consumer's problem is straight forward. With the utility function, and the cash-in-advance constraint, the first order conditions give

$$
\begin{aligned}
P_{i, t} C_{i, t} & =W_{i, t}, \\
M_{i, t} & =W_{i, t} .
\end{aligned}
$$

With the Cobb-Douglas aggregate over goods,

$$
\ln C_{i, t}=\int_{0}^{1} \ln C_{i, t}(g) d g
$$

the demand for each good is obtained by the cost minimization problem of

$$
\min _{\left\{C_{i, g}(g)\right\}} \int_{0}^{1} P_{i, t}(g) C_{i, t}(g) d g
$$

subject to (8) given $C_{i, t}$. This gives

$$
C_{i, t}(g)=\frac{P_{i, t} C_{i, t}}{P_{i, t}(g)}
$$


where $P_{i, t}$ is the consumer price index in city $i$ given by

$$
\ln P_{i, t}=\int_{0}^{1} \ln P_{i, t}(g) d g .
$$

Clearly, from (10) the market share of a good in a city is invariant to the marginal trade cost. A good is composed of brands based on the CES function

$$
C_{i, t}(g)=\left(\sum_{k=1}^{2} \int_{0}^{1} C_{i, t}(k, g, v)^{\frac{\theta-1}{\theta}} d v\right)^{\frac{\theta}{\theta-1}} .
$$

Given $C_{i, t}(g)$ the cost minimization problem of

$$
\min _{\left\{C_{i, t}(k, g, v)\right\}} \sum_{k=1}^{2} \int_{0}^{1} P_{i, t}(k, g, v) C_{i, t}(k, g, v) d v
$$

subject to (12) gives the demand for a brand

$$
\begin{aligned}
C_{i, t}(k, g, v) & =\left[\frac{P_{i, t}(k, g, v)}{P_{i, t}(g)}\right]^{-\theta} C_{i, t}(g) \\
& =\left[P_{i, t}(k, g, v)\right]^{-\theta}\left[P_{i, t}(g)\right]^{\theta-1} P_{i, t} C_{i, t},
\end{aligned}
$$

where $P_{i, t}(g)$ is the price index of good $g$ in city $i$ given by

$$
P_{i, t}(g)=\left(\sum_{k=1}^{2} \int_{0}^{1} P_{i, t}(k, g, v)^{1-\theta} d v\right)^{\frac{1}{1-\theta}} .
$$

\section{B.2 Producer's Problem}

At the beginning of each period, there are fractions of firms producing good $g$ in city $i, \phi_{j, t}(i, g)$ with $j=1,2, \ldots, J(i, g)$ which adjusted their prices $j$ periods ago to $P_{k, t-j}^{*}(i, g)=P_{k, t-j}(i, g, v) .{ }^{23}$ Among these firms, the fraction of $\alpha_{j, t}(i, g)$ firms change their prices to $P_{k, t}^{*}(i, g)$ with the payment of the fixed cost, and the remaining fraction of $1-\alpha_{j, t}(i, g)$ firms do not change their prices and keeps charging $P_{k, t-j}^{*}(i, g)$ in each city. The total fraction of price adjusting firms in period $t, \omega_{0, t}(i, g)$, is given as

$$
\omega_{0, t}(i, g)=\sum_{j=1}^{J(i, g)} \alpha_{j, t}(i, g) \phi_{j, t}(i, g) .
$$

The fraction of firms $\omega_{j, t}(i, g)=\left[1-\alpha_{j, t}(i, g)\right] \phi_{j, t}(i, g)$ with $g=1,2, \ldots, J(i, g)-1$ remain with the prices set in period $t-j$. So, in the beginning of the next period, the fraction of firms $\phi_{j, t+1}(i, g)$ satisfies $\phi_{j, t+1}(i, g)=\omega_{j-1, t}(i, g), j=1, \ldots, J(i, g)$.

Let's consider a firm with $(i, g, v)$ which set its prices $j$ periods ago, $P_{k, t-j}^{*}(i, g)$. Let the demand in city $k$ for the brand produced by the firm be $C_{k, t}^{j}(i, g)=C_{k, t}(i, g, v)$. Given the prices, the firm maximizes its profit

$$
\Pi_{t}^{j}(i, g)=\max _{L_{t}^{j}(i, g)}\left\{\sum_{k=1}^{2} P_{k, t-j}^{*}(i, g) C_{k, t}^{j}(i, g)-W_{i, t} L_{t}^{j}(i, g)\right\},
$$

\footnotetext{
${ }^{23}$ Note that as productivity is good and city specific not brand specific, the pricing decision is not brand specific.
} 
subject to the production function $Y_{t}^{j}(i, g)=Z_{t}(i, g) L_{t}^{j}(i, g)$, and the sum of demands in two cities (14) equals the output. Here, $Y_{t}^{j}(i, g)=Y_{t}(i, g, v)$, and $L_{t}^{n}(i, g)=L_{t}(i, j, v)$ are the the output and labor input of firm $(i, g, v)$ which uses the prices set $j$ periods ago. The value of the firm, excluding the payment of the fixed price adjustment cost, which resets its prices today is given as

$$
\begin{aligned}
V_{t}^{0}(i, g)=\max _{\left\{P_{k, t}^{*}(i, g)\right\}_{k=1}^{2}} & \left\{\Pi_{t}^{0}(i, g)+E_{t} \Lambda_{t+1 \mid t}\left[1-\alpha_{1, t+1}(i, g)\right] V_{t+1}^{1}(i, g)\right. \\
& \left.+E_{t} \Lambda_{t+1 \mid t}\left[\alpha_{1, t+1}(i, g) V_{t+1}^{0}(i, g)-W_{i, t+1} \Gamma_{t+1}^{1}(i, g)\right]\right\},
\end{aligned}
$$

where $\Lambda_{t+1 \mid t}$ is the stochastic discount factor in the country, and $\Gamma_{t}^{j}(i, g)=f_{g} \int_{0}^{G^{-1}\left(\alpha_{j, t}(i, g)\right)} \xi d G(\xi)$. Under the complete asset market condition, two cities have the same stochastic discount factor which is given as $\Lambda_{t+j \mid t}=\beta^{j} \frac{U_{C 1, t+j}}{U_{C 1, t}} \frac{P_{1, t}}{P_{1, t+j}}=\beta^{j} \frac{U_{C 2, t+j}}{U_{C 2, t}} \frac{P_{2, t}}{P_{2, t+j}}$, where $U_{C i, t}$ is the marginal utility of consumption in city $i$. The value of the firm which does not reset its prices is given as

$$
\begin{aligned}
V_{t}^{j}(i, g)= & \Pi_{t}^{j}(i, g)+E_{t} \Lambda_{t+1 \mid t}\left[1-\alpha_{j+1, t+1}(i, g)\right] V_{t+1}^{j+1}(i, g) \\
& +E_{t} \Lambda_{t+1 \mid t}\left[\alpha_{j+1, t+1}(i, g) V_{t+1}^{0}(i, g)-W_{i, t+1} \Gamma_{t+1}^{j+1}(i, g)\right],
\end{aligned}
$$

for $j=1,2, \ldots, J(i, g)-1$. A firm resets its prices if $V_{t}^{0}(i, g)-V_{t}^{j}(i, g) \geq W_{t} f_{g} \xi$. Thus the fraction of the firms that change their prices is given as $\alpha_{j, t}(i, g)=G\left(\frac{V_{t}^{0}(i, g)-V_{t}^{j}(i, g)}{W_{t} f_{g}}\right)$. The price changing firm's first order condition is given as

$$
0=\frac{\partial \Pi_{t}^{0}(i, g)}{\partial P_{k, t}^{*}(i, g)}+E_{t} \Lambda_{t+1 \mid t}\left[1-\alpha_{1, t+1}(i, g)\right] \frac{\partial V_{t+1}^{1}(i, g)}{\partial P_{k, t}^{*}(i, g)}
$$

We can rewrite the first order condition as

$$
P_{k, t}^{*}(i, g)=\left[\frac{\left(\frac{\theta}{\theta-1}\right) E_{t} \sum_{j=0}^{J(i, g)-1} \Lambda_{t+j \mid t}\left(\frac{\omega_{j, t+j}(i, g)}{\omega_{0, t}(i, g)}\right) P_{k, t+j}(g)^{\theta-1} P_{k, t+j} C_{k, t+j} \Psi_{k, t+j}(i, g)}{E_{t} \sum_{n=0}^{J(i, g)-1} \Lambda_{t+j \mid t}\left(\frac{\omega_{j, t+j}(i, g)}{\omega_{0, t}(i, g)}\right) P_{k, t+j}(g)^{\theta-1} P_{k, t+j} C_{k, t+j}}\right],
$$

where $\frac{\omega_{j, t+j}(i, g)}{\omega_{0, t}(i, g)}=\left[1-\alpha_{j, t+j}(i, g)\right]\left[1-\alpha_{j-1, t+j-1}(i, g)\right] \cdots\left[1-\alpha_{1, t+1}(i, g)\right]$ is the probability that the price adjusting firm in period $t$ will not adjust its prices until $t+j$; and $\Psi_{k, t+j}(i, g)$ is the effective marginal cost of production for serving a brand in city $k, \Psi_{k, t+j}(i, g)=W_{i, t+j} / Z_{t+j}(i, g)$ for $i=k$, and $\Psi_{k, t+j}(i, g)=\left(1+\tau_{g}\right) W_{i, t+j} / Z_{t+j}(i, g)$ for $i \neq k$. Note that since firms change their prices at least once in $J(i, g)$ periods due to inflation, $\omega_{j, t+j}(i, g)=0$ for $j \geq J(i, g)$. We can rewrite the price index of a good (15) with $\omega$ as

$$
P_{i, t}(g)=\left[\sum_{k=1}^{2} \sum_{j=0}^{J(k, g)-1} \omega_{j, t}(k, g) P_{i, t-j}^{*}(k, g)^{1-\theta}\right]^{\frac{1}{1-\theta}}
$$




\section{Appendix: Data Description}

Table A.1: Data Description (by product)

\begin{tabular}{|c|c|c|c|c|}
\hline Number & Item & stickiness & tradability & Descriptions \\
\hline 1 & Steak & $\mathrm{L}$ & $\mathrm{T}$ & Pound, USDA Choice \\
\hline 2 & Ground beef & $\mathrm{L}$ & $\mathrm{T}$ & Pound, lowest price \\
\hline 3 & Whole chicken & $\mathrm{L}$ & $\mathrm{T}$ & Pound, whole fryer \\
\hline 4 & Canned tuna & M & $\mathrm{T}$ & $\begin{array}{l}\text { Starkist or Chicken of the Sea; } 6.5 \text { oz. }(85.1-91.3), 6.125 \text { oz.(91.4-95.3), } \\
6-6.125 \text { oz.(95.3-99.4), 6.0 oz. (00.1-09.4) }\end{array}$ \\
\hline 5 & Milk & $\mathrm{L}$ & $\mathrm{T}$ & $1 / 2$ gal. carton \\
\hline 6 & Eggs & $\mathrm{L}$ & $\mathrm{T}$ & One Dozen, Grade A, Large \\
\hline 7 & Margarine & $\mathrm{L}$ & $\mathrm{T}$ & One Pound, Blue Bonnet or Parkay \\
\hline 8 & Cheese & $\mathrm{L}$ & $\mathrm{T}$ & Parmesan, grated 8 oz. canister, Kraft \\
\hline 9 & Potatoes & $\mathrm{L}$ & NT & 10 lbs. white or red \\
\hline 10 & Bananas & M & NT & One pound \\
\hline 11 & Lettuce & $\mathrm{L}$ & NT & Head, approximately 1.25 pounds \\
\hline 12 & Bread & M & $\mathrm{T}$ & $24 \mathrm{oz}$ loaf \\
\hline 13 & Coffee & M & $\mathrm{T}$ & $\begin{array}{l}\text { Can, Maxwell House, Hills Brothers, or Folgers; } 1 \text { lb. (85.1-88.3); } 13 \text { oz. (88.4-99.4); } \\
11.5 \text { oz. (00.1-09.4) }\end{array}$ \\
\hline 14 & Sugar & M & $\mathrm{T}$ & Cane or beet; 5 lbs. (85.1-92.3); 4 lbs. (92.4-09.4) \\
\hline 15 & Corn flakes & M & $\mathrm{T}$ & $18 \mathrm{oz}$, Kellog's or Post Toasties \\
\hline 16 & Canned peas & - & $\mathrm{T}$ & $\begin{array}{l}\text { Can, Del Monte or Green Giant; } 17 \text { oz can, } 15-17 \text { oz. (85.1-85.4), } 17 \text { oz. (86.1-91.4), } \\
\text { 15-15.25 oz. (92.1-09.4) }\end{array}$ \\
\hline 17 & Canned peaches & M & $\mathrm{T}$ & 1/2 can approx. 29 oz.; Hunt's, Del Monte, or Libby's or Lady Alberta \\
\hline 18 & Tissue & $\mathrm{H}$ & $\mathrm{T}$ & 175-count box (85.1-02.3), 200-count box (02.4-09.4); Kleenex brand \\
\hline 19 & Detergent & M & $\mathrm{T}$ & $\begin{array}{l}42 \mathrm{oz} \text {, Tide, Bold, or Cheer (85.1-96.3); } 50 \mathrm{oz.}(96.4-00.4), 60 \mathrm{oz} \text { (01.1-02.3), } \\
75 \mathrm{oz}(02.4-09.4) \text {, Cascade dishwashing powder }\end{array}$ \\
\hline 20 & Shortening & M & $\mathrm{T}$ & 3 lbs. can, all-vegetable, Crisco brand \\
\hline 21 & Frozen corn & M & $\mathrm{T}$ & 10 oz. (85.1-95.3), 16 oz. (95.4-09.4); Whole Kernel \\
\hline 22 & Soft drink & M & $\mathrm{T}$ & 2 liter Coca Cola \\
\hline 23 & Apartment rent & $\mathrm{L}$ & NT & $\begin{array}{l}\text { Two-Bedroom, unfurnished, excluding all utilities except water, } 1.2 \text { or } 2 \text { baths, } \\
\text { approx. } 950 \mathrm{sqft}\end{array}$ \\
\hline 24 & Home price & - & NT & $\begin{array}{l}1,800 \text { sqft, new house, } 8,000 \text { sqft lot, }(85.1-99.4) ; \\
2,400 \text { sqft, new house, } 8,000 \text { sqft lot, } 4 \text { bedrooms, } 2 \text { baths }(00.1-09.4)\end{array}$ \\
\hline 25 & Monthly payment & - & NT & Principal and Interest, assuming $25 \%$ down payment \\
\hline 26 & Telephone & M & NT & Private residential line, basic monthly rate, fees and taxes \\
\hline 27 & Auto maintenance & M & NT & $\begin{array}{l}\text { average price to balance one front wheel }(85.1-88.3) \text {; } \\
\text { average price to computer or spin balance one front wheel (88.4-09.4) }\end{array}$ \\
\hline 28 & Gas & $\mathrm{L}$ & $\mathrm{T}$ & One gallon regular unleaded, national brand, including all taxes \\
\hline 29 & Doctor visit & $\mathrm{H}$ & NT & General practitioner's routine examination of established patient \\
\hline 30 & Dentist visit & $\mathrm{H}$ & NT & $\begin{array}{l}\text { Adult teeth cleaning and periodic oral examination (85.1-04.4); } \\
\text { Adult teeth cleaning }(05.1-09.1)\end{array}$ \\
\hline 31 & McDonald's & $\mathrm{H}$ & NT & McDonald's Quarter-Pounder with Cheese \\
\hline 32 & Pizza & $\mathrm{M}$ & NT & $\begin{array}{l}\text { 12"-13" (85.1-94.3), 11"-12" (94.4-09.4) thin crust cheese pizza, } \\
\text { Pizza Hut or Pizza Inn from 1990Q1 to 1994Q3 }\end{array}$ \\
\hline 33 & Fried chicken & $\mathrm{M}$ & NT & Thigh and Drumstick, KFC or Church's where available \\
\hline 34 & Man's haircut & - & NT & Man's barber shop haircut, no styling \\
\hline 35 & Beauty salon & $\mathrm{H}$ & NT & Woman's shampoo, trim, and blow dry \\
\hline 36 & Toothpaste & $\mathrm{H}$ & $\mathrm{T}$ & 6 to 7 oz. tube (85.1-06.2), 6 oz- $6.4 \mathrm{oz}$ tube (06.3-09.4); Crest, or Colgate \\
\hline 37 & Dry cleaning & $\mathrm{H}$ & NT & Man's two-piece suit \\
\hline 38 & Man's shirt & $\mathrm{H}$ & NT & $\begin{array}{l}\text { Arrow, Enro, Van Huesen, or JC Penny's Stafford, White, cotton/polyester blend } \\
\text { (at least } 55 \% \text { cotton) long sleeves (85.1-94.3); } 100 \% \text { cotton pinpoint Oxford, } \\
\text { Long sleeves }(94.4-99.4) \text { Cotton/Polyester, pinpoint weave, long sleeves (00.1-09.4) }\end{array}$ \\
\hline 39 & Appliance repair & M & NT & Home service call, washing machine, excluding parts \\
\hline 40 & Newspaper & $\mathrm{H}$ & $\mathrm{T}$ & Daily and Sunday home delivery, large-city newspaper, monthly rate \\
\hline 41 & Movie & M & NT & First-run, indoor, evening, no discount \\
\hline 42 & Bowling & $\mathrm{H}$ & NT & Price per line, evening rate (85.1-98.2); Saturday evening non-league rate (98.3-09.4) \\
\hline 43 & Tennis balls & $\mathrm{H}$ & NT & Can of three extra duty, yellow, Wilson or Penn Brand \\
\hline 44 & Beer & M & $\mathrm{T}$ & $\begin{array}{l}\text { 6-pack, } 12 \text { oz containers, excluding deposit; Budweiser or Miller Lite, (85.1-99.4), } \\
\text { Heineken's (00.1-09.4) }\end{array}$ \\
\hline 45 & Wine & $\mathrm{H}$ & $\mathrm{T}$ & $\begin{array}{l}\text { 1.5-liter bottle; Paul Masson Chablis (85.1-90.3) } \\
\text { Gallo sauvignon blanc }(90.4-91.3) \text {, Gallo chablis blanc }(91.4-97.3) \\
\text { Livingston Cellars or Gallo chablis blanc }(97.1-00.1) \\
\text { Livingston Cellars or Gallo chablis or Chenin blanc }(00.2-09.4)\end{array}$ \\
\hline
\end{tabular}


Table A.2: Data Description (by city)

\begin{tabular}{|c|c|c|c|c|c|}
\hline City code & City name & State & $\begin{array}{r}\text { Income } \\
\text { (dollars) }\end{array}$ & $\begin{array}{c}\text { Population } \\
\text { (thousands) }\end{array}$ & $\overline{\mathrm{CPI}}$ \\
\hline 1 & ABILENE & TX & 16,938 & 140 & 0.814 \\
\hline 2 & AMARILLO & TX & 17,905 & 218 & 0.805 \\
\hline 3 & ATLANTA & GA & 21,560 & 4,143 & 0.925 \\
\hline 4 & CEDAR RAPIDS & IA & 20,238 & 212 & 0.826 \\
\hline 5 & CHARLOTTE & $\mathrm{NC}$ & 21,190 & 1,402 & 0.865 \\
\hline 6 & CHATTANOOGA & $\mathrm{TN}$ & 18,196 & 470 & 0.844 \\
\hline 7 & CLEVELAND & $\mathrm{OH}$ & 16,100 & 2,173 & 0.903 \\
\hline 8 & COLORADO SPRINGS & $\mathrm{CO}$ & 19,419 & 519 & 0.864 \\
\hline 9 & COLUMBIA & $\mathrm{MO}$ & 18,078 & 139 & 0.830 \\
\hline 10 & COLUMBIA & $\mathrm{SC}$ & 18,213 & 589 & 0.817 \\
\hline 11 & DALLAS & TX & 22,536 & 3,423 & 0.900 \\
\hline 12 & DENVER & $\mathrm{CO}$ & 24,482 & 2,082 & 0.933 \\
\hline 13 & DOVER & $\mathrm{DE}$ & 16,840 & 131 & 0.901 \\
\hline 14 & FAYETTEVILLE & $\mathrm{AR}$ & 16,449 & 125 & 0.768 \\
\hline 15 & GLENS FALLS & NY & 16,747 & 124 & 0.911 \\
\hline 16 & GREENVILLE & $\mathrm{NC}$ & 16,319 & 142 & 0.811 \\
\hline 17 & HOUSTON & $\mathrm{TX}$ & 22,862 & 4,703 & 0.870 \\
\hline 18 & HUNTSVILLE & $\mathrm{AL}$ & 19,450 & 347 & 0.832 \\
\hline 19 & JONESBORO & $\mathrm{AR}$ & 14,821 & 93 & 0.749 \\
\hline 20 & JOPLIN & $\mathrm{MO}$ & 15,555 & 154 & 0.760 \\
\hline 21 & KNOXVILLE & $\mathrm{TN}$ & 18,463 & 646 & 0.787 \\
\hline 22 & LEXINGTON & KY & 20,257 & 435 & 0.856 \\
\hline 23 & LOS ANGELES & $\mathrm{CA}$ & 22,628 & 9,406 & 0.797 \\
\hline 24 & LOUISVILLE & KY & 19,914 & 1,094 & 1.039 \\
\hline 25 & LUBBOCK & TX & 16,951 & 245 & 1.005 \\
\hline 26 & MEMPHIS & $\mathrm{TN}$ & 19,617 & 1,157 & 0.859 \\
\hline 27 & MOBILE & $\mathrm{AL}$ & 15,404 & 456 & 0.904 \\
\hline 28 & MONTGOMERY & AL & 18,062 & 334 & 0.793 \\
\hline 29 & ODESSA & $\mathrm{TX}$ & 16,271 & 180 & 0.813 \\
\hline 30 & OKLAHOMA CITY & OK & 19,120 & 1,080 & 0.829 \\
\hline 31 & ОМАНА & NE & 21,435 & 738 & 0.830 \\
\hline 32 & PHILADELPHIA & PA & 23,417 & 4,435 & 0.979 \\
\hline 33 & PHOENIX & $\mathrm{AZ}$ & 19,604 & 3,218 & 0.874 \\
\hline 34 & PORTLAND & OR & 21,454 & 1,889 & 0.905 \\
\hline 35 & RALEIGH & $\mathrm{NC}$ & 21,780 & 967 & 0.883 \\
\hline 36 & RENO-SPARKS & NV & 24,832 & 337 & 0.956 \\
\hline 37 & RIVERSIDE & $\mathrm{CA}$ & 17,365 & 3,345 & 0.978 \\
\hline 38 & SALT LAKE CITY & UT & 18,863 & 111 & 0.924 \\
\hline 39 & SAN ANTONIO & TX & 17,870 & 1,661 & 0.812 \\
\hline 40 & SOUTHBEND & IN & 18,663 & 1,117 & 0.798 \\
\hline 41 & SPRINGFIELD & IL & 20,742 & 2,796 & 0.807 \\
\hline 42 & ST. CLOUD & $\mathrm{MN}$ & 16,813 & 169 & 0.859 \\
\hline 43 & ST. LOUIS & MO & 21,488 & 202 & 0.848 \\
\hline 44 & SYRACUSE & NY & 19,071 & 696 & 0.873 \\
\hline 45 & TACOMA & WA & 24,715 & 695 & 0.881 \\
\hline 46 & TUCSON & $\mathrm{AZ}$ & 17,189 & 838 & 0.855 \\
\hline 47 & WACO & TX & 16,279 & 210 & 0.810 \\
\hline 48 & YORK & PA & 20,124 & 383 & 0.868 \\
\hline
\end{tabular}

Note: Both the city-level per capita nominal income and population data are downloaded from the website of Census Bureau in BEA, and the city-level CPI data are borrowed from Carrillo et al. (2010) who created the panel of annual price indices entitled 'CEOPricesPanel02' that cover the period 1982 through 2008 for most metropolitan areas in the United States. 
Table A.3: Data description of explantary variables

\begin{tabular}{clc}
\hline \hline Variable & \multicolumn{1}{c}{ Description } & \multicolumn{1}{c}{ Source } \\
\hline Distance & $\begin{array}{l}\text { The great circle distance computed by using the latitude } \\
\text { and longitude of each city }\end{array}$ & $\begin{array}{l}\text { The American Practical } \\
\text { Navigator (relevant website) }\end{array}$ \\
Average personal income of the U.S. Metropolitan area & BEA website \\
Puring 1976-2009 & $\begin{array}{l}\text { Average populations of the U.S. Metropolitan area during } \\
\text { 1976-2009 }\end{array}$ & Census Bureau website \\
Price & $\begin{array}{l}\text { Average city-level CPI of metropolitan area in the U.S. } \\
\text { during 1982-2008 }\end{array}$ & Carrillo et al. (2010) \\
Price rigidity & $\begin{array}{l}\text { Frequency of price changes for non-shelter consumer prices } \\
\text { in the U.S. for some 270 entry-level items for the period } \\
\text { 1998-2005 }\end{array}$ & Nakamura and Steinsson (2008) \\
Distribution margin & $\begin{array}{l}\text { Difference between what final consumers pay and what producers } \\
\text { receive that encompasses all the real costs associated with } \\
\text { the movement of goods and services from the producer to the } \\
\text { consumer plus markups over marginal cost }\end{array}$ & Crucini and Shintani (2008) \\
\hline \hline
\end{tabular}


Table 1: Summary of previous studies

\begin{tabular}{|c|c|c|c|c|c|}
\hline Study & Model & Nominal rigidities & Market friction & $\overline{\text { Data }}$ & Empirical results \\
\hline $\begin{array}{l}\text { Carvalho and } \\
\text { Nechio (2011) }\end{array}$ & $\begin{array}{l}\text { Multi-sector, } \\
\text { two country } \\
\text { GE model }\end{array}$ & $\begin{array}{l}\text { Infrequency of } \\
\text { price changes }\end{array}$ & n.a. & $\begin{array}{l}\text { Eurostat data } \\
\text { borrowed from } \\
\text { Imbs et al. (2005) }\end{array}$ & $\begin{array}{l}\text { Volatility and persistence } \\
\text { of sectoral RERs increase } \\
\text { with nominal rigiditieis }\end{array}$ \\
\hline CST (2012) & $\begin{array}{l}\text { An extended } \\
\text { model of CST (2010) } \\
\text { with imperfect } \\
\text { commmon knowledge }\end{array}$ & $\begin{array}{l}\text { Infrequency of } \\
\text { price changes }\end{array}$ & $\begin{array}{l}\text { Physical } \\
\text { distance }\end{array}$ & $\begin{array}{l}\text { ACCRA data for } \\
48 \text { items in } \\
52 \text { US cities } \\
\text { 1990:Q1-2007:Q4 }\end{array}$ & $\begin{array}{l}\text { Positive correlation of } \\
\text { volatility and persistence } \\
\text { of LOP deviation with } \\
\text { transportation costs }\end{array}$ \\
\hline ER (1996) & $\begin{array}{l}\text { Basic gravity } \\
\text { model }\end{array}$ & $\begin{array}{l}\text { Relative real } \\
\text { prices as a } \\
\text { proxy }\end{array}$ & $\begin{array}{l}\text { Physical } \\
\text { distance }\end{array}$ & $\begin{array}{l}14 \text { disaggregated } \\
\text { CPI data for } 23 \\
\text { North American cities } \\
\text { for 1978:M6-1994:M12 }\end{array}$ & $\begin{array}{l}\text { Distance matters for } \\
\text { relative price variability }\end{array}$ \\
\hline $\begin{array}{c}\text { Kehoe and } \\
\text { Midrigan (2011) }\end{array}$ & $\begin{array}{l}\text { Multi-sector } \\
\text { GE model with } \\
\text { sticky price }\end{array}$ & $\begin{array}{l}\text { Infrequency of } \\
\text { price change }\end{array}$ & n.a. & $\begin{array}{l}66 \text { disaggregated } \\
\text { CPI data for US } \\
\text { and European } \\
\text { countries }\end{array}$ & $\begin{array}{l}\text { Positive association of } \\
\text { price stickiness with } \\
\text { persistence but negative } \\
\text { association with volatility } \\
\text { of sectoral RERs }\end{array}$ \\
\hline
\end{tabular}


Table 2: Summary statistics on average intercity price difference and its dynamic properties

\begin{tabular}{|c|c|c|c|c|c|}
\hline \multirow[t]{2}{*}{ item } & \multicolumn{3}{|c|}{ average log price differences } & volatility & persistence \\
\hline & mean & $\min$ & $\max$ & mean $[5 \%, 95 \%]$ & mean $[5 \%, 95 \%]$ \\
\hline 1 & 0.134 & 0.060 & 0.280 & $0.14[0.09,0.20]$ & $0.60[0.16,0.92]$ \\
\hline 2 & 0.178 & 0.080 & 0.424 & $0.19[0.13,0.26]$ & $0.60[0.22,0.87]$ \\
\hline 3 & 0.193 & 0.073 & 0.413 & $0.18[0.13,0.24]$ & $0.61[0.22,0.87]$ \\
\hline 4 & 0.167 & 0.063 & 0.435 & $0.17[0.11,0.24]$ & $0.66[0.30,0.89]$ \\
\hline 5 & 0.141 & 0.049 & 0.302 & $0.13[0.08,0.20]$ & $0.79[0.49,0.95]$ \\
\hline 6 & 0.188 & 0.066 & 0.775 & $0.16[0.11,0.25]$ & $0.55[0.12,0.88]$ \\
\hline 7 & 0.203 & 0.079 & 0.585 & $0.20[0.13,0.28]$ & $0.68[0.34,0.93]$ \\
\hline 8 & 0.116 & 0.033 & 0.323 & $0.11[0.07,0.17]$ & $0.77[0.40,0.99]$ \\
\hline 9 & 0.240 & 0.093 & 0.568 & $0.23[0.18,0.29]$ & $0.53[0.15,0.85]$ \\
\hline 10 & 0.175 & 0.077 & 0.468 & $0.19[0.13,0.26]$ & $0.61[0.24,0.86]$ \\
\hline 11 & 0.188 & 0.088 & 0.433 & $0.21[0.15,0.27]$ & $0.57[0.12,0.89]$ \\
\hline 12 & 0.221 & 0.089 & 0.552 & $0.21[0.15,0.31]$ & $0.69[0.33,0.93]$ \\
\hline 13 & 0.143 & 0.049 & 0.352 & $0.13[0.09,0.18]$ & $0.67[0.32,0.91]$ \\
\hline 14 & 0.121 & 0.045 & 0.359 & $0.13[0.08,0.19]$ & $0.63[0.32,0.86]$ \\
\hline 15 & 0.160 & 0.056 & 0.326 & $0.17[0.11,0.24]$ & $0.74[0.41,0.92]$ \\
\hline 16 & 0.157 & 0.071 & 0.384 & $0.16[0.12,0.20]$ & $0.65[0.28,0.90]$ \\
\hline 17 & 0.109 & 0.035 & 0.297 & $0.11[0.07,0.18]$ & $0.73[0.34,0.98]$ \\
\hline 18 & 0.116 & 0.048 & 0.296 & $0.12[0.09,0.16]$ & $0.66[0.32,0.91]$ \\
\hline 19 & 0.130 & 0.058 & 0.263 & $0.14[0.10,0.18]$ & $0.69[0.38,0.91]$ \\
\hline 20 & 0.120 & 0.034 & 0.309 & $0.12[0.07,0.17]$ & $0.79[0.56,0.93]$ \\
\hline 21 & 0.151 & 0.073 & 0.299 & $0.18[0.12,0.26]$ & $0.72[0.35,0.98]$ \\
\hline 22 & 0.153 & 0.081 & 0.321 & $0.16[0.12,0.22]$ & $0.61[0.24,0.89]$ \\
\hline 23 & 0.208 & 0.035 & 0.863 & $0.12[0.07,0.20]$ & $0.87[0.71,0.98]$ \\
\hline 24 & 0.188 & 0.037 & 0.891 & $0.13[0.07,0.21]$ & $0.87[0.73,0.96]$ \\
\hline 25 & 0.188 & 0.044 & 0.905 & $0.13[0.07,0.22]$ & $0.86[0.71,0.96]$ \\
\hline 26 & 0.217 & 0.043 & 0.661 & $0.16[0.08,0.28]$ & $0.85[0.67,0.98]$ \\
\hline 27 & 0.158 & 0.051 & 0.487 & $0.14[0.08,0.22]$ & $0.74[0.42,0.95]$ \\
\hline 28 & 0.073 & 0.026 & 0.195 & $0.07[0.05,0.11]$ & $0.53[0.14,0.83]$ \\
\hline 29 & 0.162 & 0.067 & 0.404 & $0.15[0.10,0.22]$ & $0.80[0.55,0.97]$ \\
\hline 30 & 0.193 & 0.056 & 0.682 & $0.15[0.09,0.21]$ & $0.79[0.55,0.95]$ \\
\hline 31 & 0.060 & 0.026 & 0.137 & $0.07[0.04,0.11]$ & $0.67[0.27,0.92]$ \\
\hline 32 & 0.092 & 0.024 & 0.250 & $0.10[0.06,0.15]$ & $0.75[0.51,0.93]$ \\
\hline 33 & 0.129 & 0.046 & 0.326 & $0.12[0.08,0.17]$ & $0.69[0.33,0.91]$ \\
\hline 34 & 0.161 & 0.040 & 0.483 & $0.14[0.08,0.20]$ & $0.77[0.50,0.93]$ \\
\hline 35 & 0.213 & 0.065 & 0.561 & $0.18[0.11,0.27]$ & $0.77[0.47,0.96]$ \\
\hline 36 & 0.144 & 0.068 & 0.346 & $0.15[0.11,0.20]$ & $0.70[0.37,0.94]$ \\
\hline 37 & 0.155 & 0.036 & 0.458 & $0.11[0.05,0.17]$ & $0.79[0.54,0.97]$ \\
\hline 38 & 0.153 & 0.070 & 0.316 & $0.18[0.13,0.24]$ & $0.67[0.37,0.95]$ \\
\hline 39 & 0.169 & 0.055 & 0.585 & $0.15[0.10,0.28]$ & $0.77[0.52,0.96]$ \\
\hline 40 & 0.257 & 0.049 & 0.860 & $0.18[0.08,0.32]$ & $0.83[0.52,1.01]$ \\
\hline 41 & 0.113 & 0.026 & 0.515 & $0.10[0.05,0.20]$ & $0.78[0.49,0.96]$ \\
\hline 42 & 0.186 & 0.050 & 0.523 & $0.15[0.09,0.26]$ & $0.76[0.48,0.95]$ \\
\hline 43 & 0.158 & 0.062 & 0.381 & $0.16[0.11,0.23]$ & $0.72[0.43,0.91]$ \\
\hline 44 & 0.092 & 0.030 & 0.287 & $0.09[0.05,0.15]$ & $0.73[0.44,0.91]$ \\
\hline 45 & 0.165 & 0.022 & 0.430 & $0.14[0.10,0.19]$ & $0.67[0.37,0.90]$ \\
\hline Average & 0.159 & 0.054 & 0.451 & 0.15 & 0.71 \\
\hline
\end{tabular}

Note: Entries represent mean, minimum, maximum, and volatility measures of period-average absolute log price difference, $\frac{1}{T} \sum_{t=1}^{T}\left|\ln P_{i t}^{h}-\ln P_{j t}^{h}\right|$, where $\ln P_{i t}^{h}-\ln P_{j t}^{h}$ measures the percentage difference between the price of product $h$ in cities $i$ and $j$ at time $t$. 
Table 3: Pooling regression results

\begin{tabular}{lccccc}
\hline \hline Regressor & \multicolumn{2}{c}{ Persistence as regressand } & & \multicolumn{2}{c}{ Volatility as regressand } \\
\cline { 2 - 3 } \cline { 5 - 6 } & $\log ($ dist $)$ & TC & & $\log ($ dist $)$ & TC \\
\hline Market friction & $0.0177 \ddagger$ & $0.0453 \ddagger$ & & $0.0073 \ddagger$ & $0.0256 \ddagger$ \\
& $(0.0011)$ & $(0.0040)$ & & $(0.0003)$ & $(0.0011)$ \\
Nominal rigidity & $0.0018 \ddagger$ & $0.0018 \ddagger$ & & $-0.0001 \ddagger$ & $-0.0001 \ddagger$ \\
& $(0.0000)$ & $(0.0000)$ & & $(0.0000)$ & $(0.0000)$ \\
POPULATION & $0.0229 \ddagger$ & $0.0228 \ddagger$ & & $0.0081 \ddagger$ & $0.0079 \ddagger$ \\
& $(0.0025)$ & $(0.0025)$ & & $(0.0007)$ & $(0.0007)$ \\
RINCOME & 0.0334 & 0.0495 & & $0.0332 \ddagger$ & $0.0341 \ddagger$ \\
& $(0.0385)$ & $(0.0386)$ & & $(0.0102)$ & $(0.0102)$ \\
SAMESTATE & -0.0480 & -0.0465 & & $-0.0084 \ddagger$ & $-0.0037 \ddagger$ \\
& $(0.0039)$ & $(0.0043)$ & $(0.0009)$ & $(0.0010)$ \\
\hline \hline
\end{tabular}

Note: The estimation result is from pooling regression equation

$Y_{i j}^{p}=\sum_{h=1}^{N} \gamma_{h} D_{h}^{C}+\beta_{1}$ MarFric $_{i j}+\beta_{2}$ NomFric $^{p}+\beta_{3}$ POPULATION P $_{i j}+\beta_{4}$ RINCOME $_{i j}+\beta_{5} S A M E S T A T E_{i j}+\varepsilon_{i j}$,

where $D_{i}^{C}$ is a city dummy and $M a r F r i c_{i j}$ denotes market friction between city-pair of $(i, j)$ based on either bandwidth (BW) estimates or log distance. Nom - Fric $^{p}$ represents the degree of nominal friction for product $p$, which is measured by the expected duration of price spells based on $d=-1 / \ln (1-f)$ where $f$ is the median frequency of price changes borrowed from Nakamura and Steinsson (2008). The remaining regressors are the relative size of city-pair to the entire city-pairs, which are computed by $\frac{\max \left(z_{i}, z_{j}\right)-\min \left(z_{i}, z_{j}\right)}{\max \left(z_{i}, z_{j}\right)}$ where $z_{k}$ denotes the variable $z$ for city $k$. Distance is measured by the great circle distance between cities. The numbers in parentheses report the standard errors after correcting for heteroskedasticity. ${ }^{*}, \dagger$, and $\ddagger$ indicate statistical significance at the $1 \%, 5 \%$, and $10 \%$ error levels and heteroskedasticity robust standard errors are used. Each regression is based on 1,275 observations of intercity relative prices. 
Table 4: Group-by-group regression results on marginal effects of market friction

\begin{tabular}{|c|c|c|c|c|c|}
\hline \multirow[t]{2}{*}{ sample } & \multirow[t]{2}{*}{ regressor } & \multicolumn{2}{|c|}{ persistence } & \multicolumn{2}{|c|}{ volatility } \\
\hline & & $\log$ (dist) & $\mathrm{TC}$ & $\log$ (dist) & $\mathrm{TC}$ \\
\hline \multicolumn{6}{|c|}{ By price flexibility } \\
\hline \multirow{5}{*}{$\begin{array}{l}\text { Low-sticky } \\
\text { group }\end{array}$} & MARKET FRICTION & $0.028 \ddagger$ & $0.080 \ddagger$ & $0.008 \ddagger$ & $0.025 \ddagger$ \\
\hline & POPULATION & $0.162 \ddagger$ & $0.150 \ddagger$ & $0.024 \ddagger$ & $0.020 \ddagger$ \\
\hline & RINCOME & 0.145 & 0.173 & 0.019 & 0.028 \\
\hline & SAME STATE & $-0.057 \ddagger$ & $-0.051 \ddagger$ & $-0.012 \ddagger$ & $-0.009 \ddagger$ \\
\hline & $\operatorname{Adj}-R^{2}$ & 0.274 & 0.272 & 0.722 & 0.721 \\
\hline \multirow{5}{*}{$\begin{array}{l}\text { Medium-sticky } \\
\text { group }\end{array}$} & MARKET FRICTION & $0.019 \ddagger$ & $0.054 \ddagger$ & $0.005 \ddagger$ & $0.012 \ddagger$ \\
\hline & POPULATION & $0.065^{*}$ & 0.057 & 0.010 & 0.008 \\
\hline & RINCOME & 0.143 & 0.163 & 0.018 & 0.023 \\
\hline & SAME STATE & $-0.088 \ddagger$ & $-0.084 \ddagger$ & $-0.019 \ddagger$ & $-0.019 \ddagger$ \\
\hline & Adj- $R^{2}$ & 0.157 & 0.156 & 0.525 & 0.524 \\
\hline \multirow{5}{*}{$\begin{array}{l}\text { High-sticky } \\
\text { group }\end{array}$} & MARKET FRICTION & $0.005^{*}$ & 0.012 & $0.002 \ddagger$ & $0.005 \ddagger$ \\
\hline & POPULATION & 0.061 & 0.059 & 0.008 & 0.007 \\
\hline & RINCOME & -0.066 & -0.062 & 0.026 & 0.028 \\
\hline & SAME STATE & $-0.025 \ddagger$ & $-0.025 \ddagger$ & $-0.007 \ddagger$ & $-0.006 \ddagger$ \\
\hline & $\operatorname{Adj}-R^{2}$ & 0.141 & 0.141 & 0.435 & 0.435 \\
\hline \multicolumn{6}{|c|}{ By distribution margin (non-tradability) } \\
\hline \multirow{5}{*}{$\begin{array}{l}\text { More-tradable } \\
\text { group }\end{array}$} & MARKET FRICTION & $0.025 \ddagger$ & $0.078 \ddagger$ & $0.006 \ddagger$ & $0.017 \ddagger$ \\
\hline & POPULATION & $0.097 \ddagger$ & $0.087 \ddagger$ & $0.018 \ddagger$ & $0.016 \ddagger$ \\
\hline & RINCOME & 0.227 & 0.253 & 0.026 & 0.032 \\
\hline & SAME STATE & $-0.082 \ddagger$ & $-0.073 \ddagger$ & $-0.018 \ddagger$ & $-0.016 \ddagger$ \\
\hline & Adj- $R^{2}$ & 0.168 & 0.167 & 0.559 & 0.558 \\
\hline \multirow{5}{*}{$\begin{array}{l}\text { Less-tradable } \\
\text { group }\end{array}$} & MARKET FRICTION & $0.009 \ddagger$ & $0.017 \ddagger$ & $0.004 \ddagger$ & $0.012 \ddagger$ \\
\hline & POPULATION & $0.074 \ddagger$ & $0.069 \ddagger$ & 0.008 & 0.006 \\
\hline & RINCOME & -0.074 & -0.066 & 0.010 & 0.015 \\
\hline & SAME STATE & $-0.030 \ddagger$ & $-0.033 \ddagger$ & $-0.007 \ddagger$ & $-0.006 \ddagger$ \\
\hline & $\operatorname{Adj}-R^{2}$ & 0.279 & 0.278 & 0.554 & 0.554 \\
\hline
\end{tabular}

Note: Regression equations are

$$
y_{i j}^{k}=\beta_{1} M F_{i j}+\beta_{3} \text { POPULATION }{ }_{i j}+\beta_{4} R I N C O M E_{i j}+\beta_{5} S A M E S T A T E_{i j}+\delta_{k} D_{k}^{P}+\sum_{h=1}^{N} \gamma_{h} D_{h}^{C}+\varepsilon_{i j},
$$

where $\delta_{k} D_{k}^{P}$ denotes product dummies and $D_{h}^{C}$ denotes city dummies. 'POPULATION' and 'RINCOME' respectively represent inter-city differences of real per capita population and real income, which are computed by $\frac{\max \left(z_{i}, z_{j}\right)-\min \left(z_{i}, z_{j}\right)}{\max \left(z_{i}, z_{j}\right)}$ where $z_{k}$ denotes the variable $z$ for city $k$. SameState ${ }_{i j}$ represents a intra-state dummy variable which takes one if two cities $i$ and $j$ are in the same state and zero otherwise. 'Market friction' $\left(M F_{i j}\right)$ is measured either by physical distance between cities $i$ and $j$ or by iceberg trade costs among U.S. counties constructed by Allen and Arkolakis (forthcoming). Persistence of $\log$ price differences is estimated within a linear AR(p) model and volatility represents temporal volatility of price difference measured by standard deviation. The numbers in parentheses report the standard errors after correcting for heteroskedasticity. $\ddagger, \dagger$, and $*$ indicate statistical significance at the $1 \%, 5 \%$, and $10 \%$ error levels and heteroskedasticity robust standard errors are used. 


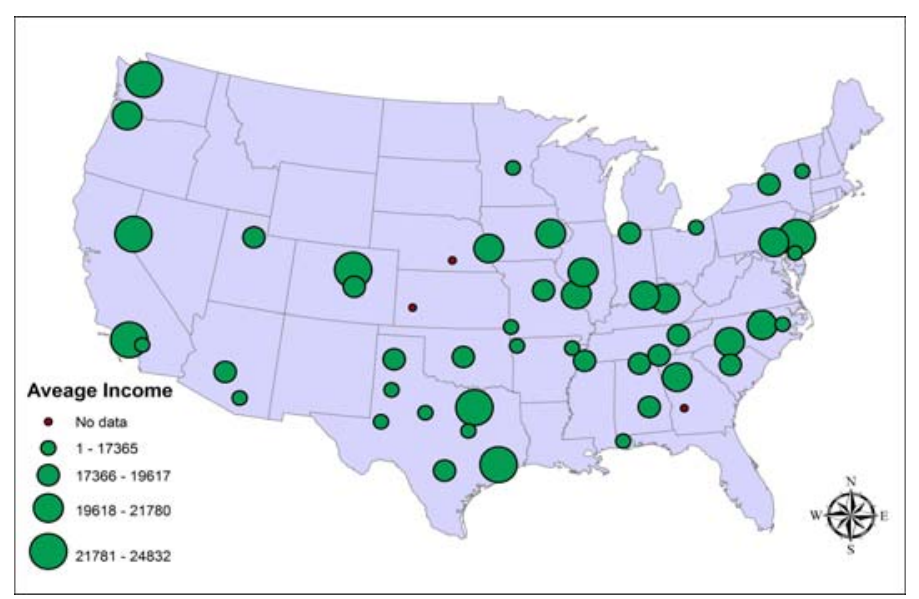

Nominal per capita income

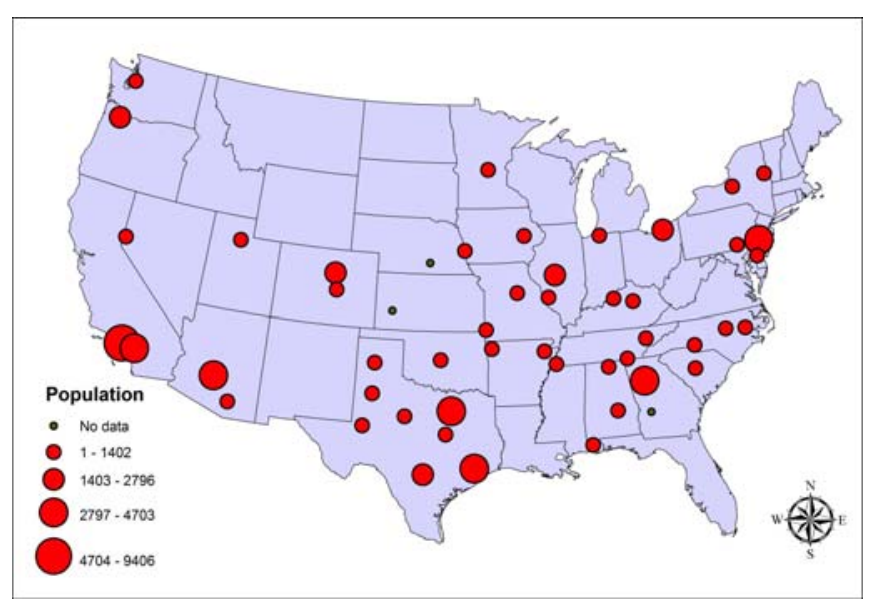

Population

Figure 1: Income and population of the U.S. Cities

Note: The figure maps the location of each city and the size of the circle denotes the size of the city in terms of per capita income (left) and population (right). 


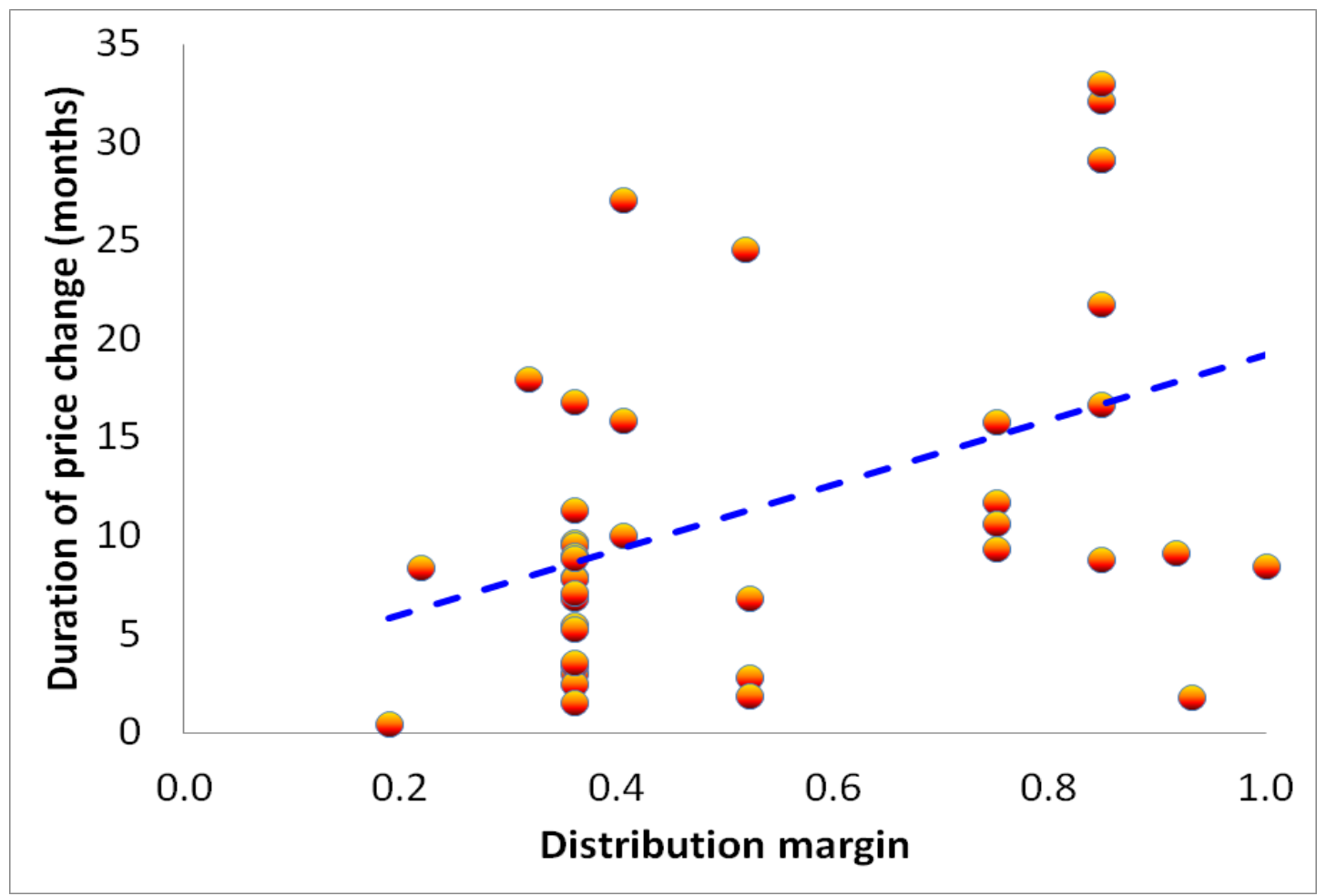

Figure 2: Distribution margin $(\mathrm{H})$ and duration of price changes (V) 


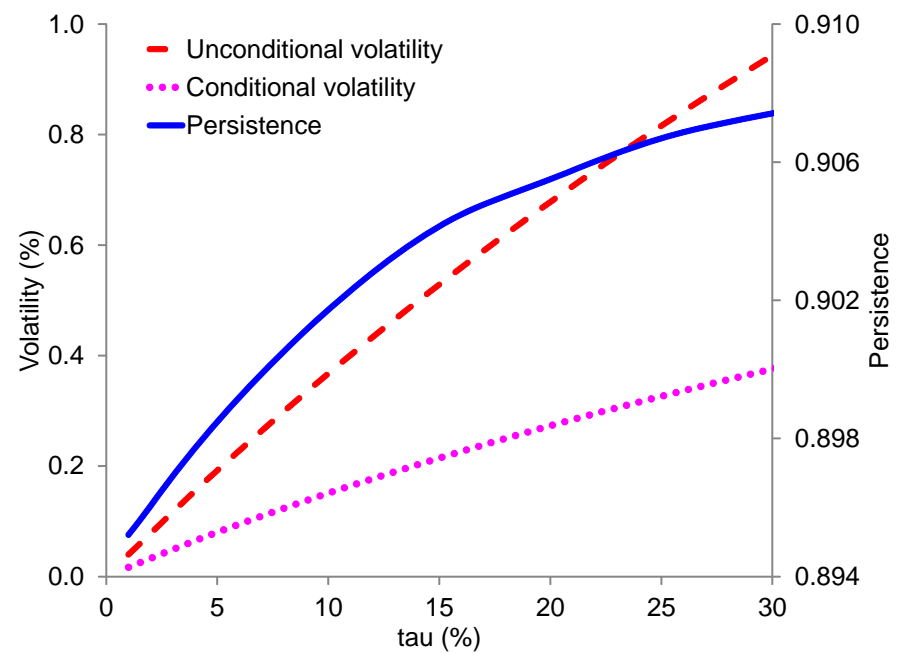

$<$ Effect of market friction $>$

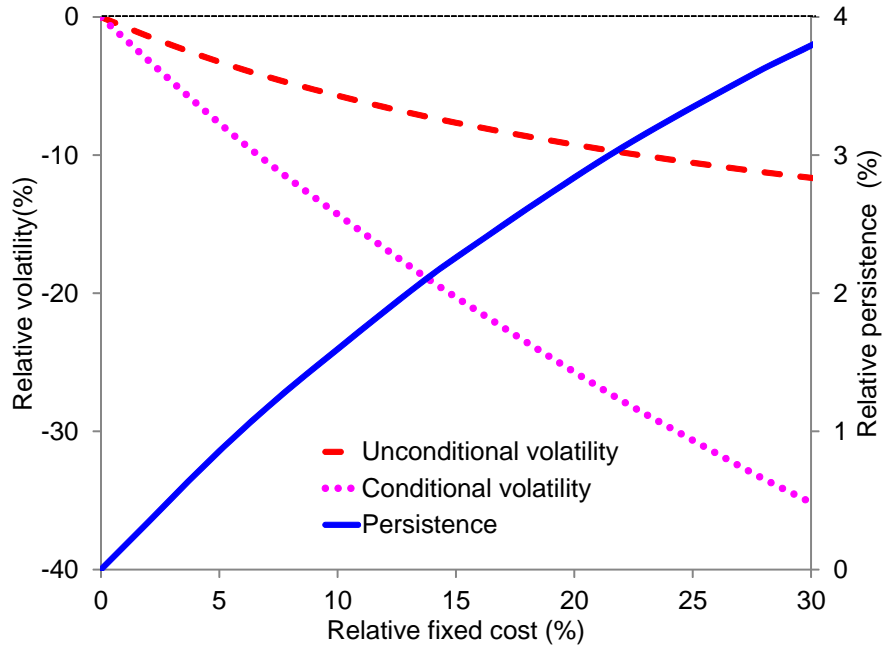

$<$ Effect of nominal rigidity $>$

Figure 3: Effects of two frictions on the dynamics of intercity price differences 
(a) Conditional volatility

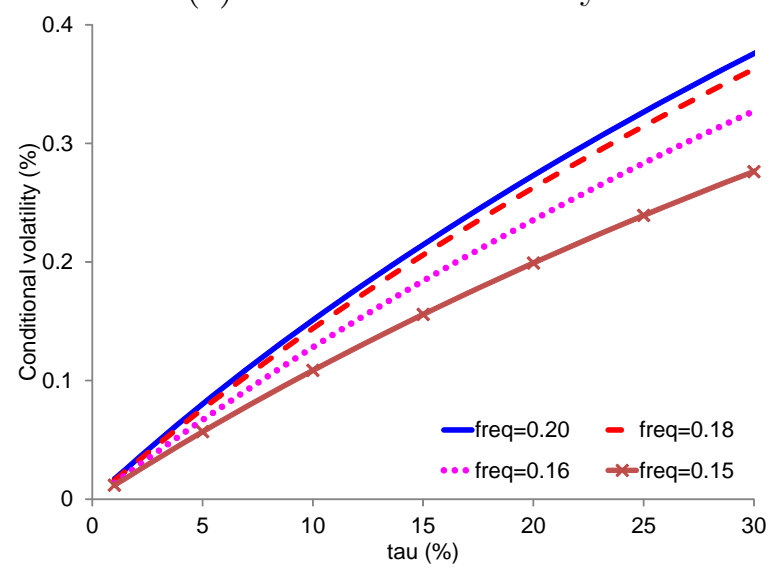

(b) Unconditional volatility

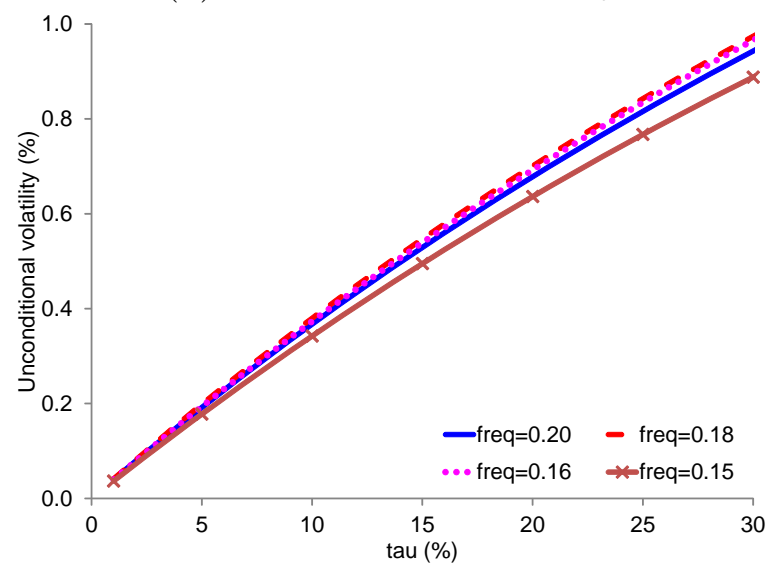

(c) Persistence

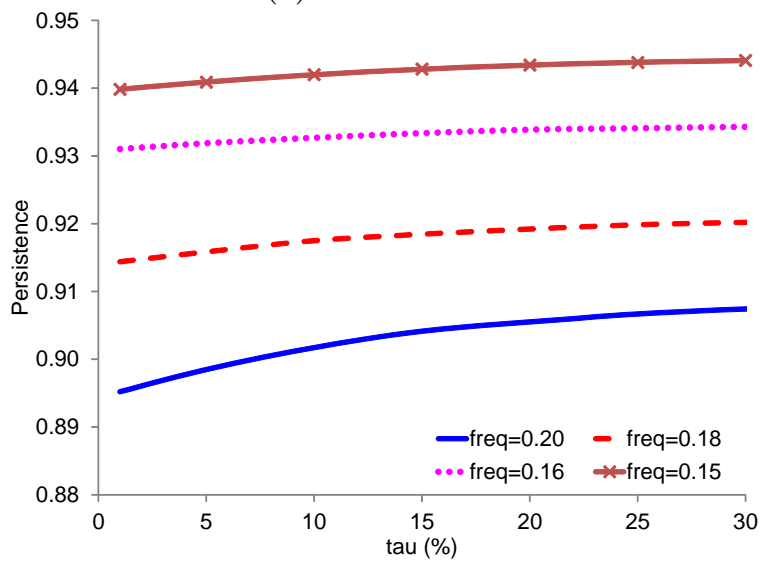

Figure 4: Marginal effect of market friction for various levels of nominal rigidity 